\title{
La transparencia como principio vertebrador de la contratación pública: significado y problemas de articulación normativa ${ }^{1}$
}

\section{Transparency as the backbone of public procurement: the meaning and problematic of normative articulation}

\author{
Isabel González Ríos \\ ORCID: https://orcid.org/0000-0002-8833-6427 \\ Universidad de Málaga (España) \\ isa_gonzalez@uma.es
}

NOTA BIOGRÁFICA

Catedrática de Derecho Administrativo de la Universidad de Málaga. Entre sus líneas de investigación destacan: los bienes públicos; la sanidad animal y la seguridad alimentaria; las energías renovables y la eficiencia energética; el turismo; los servicios de interés general; la racionalización administrativa y el procedimiento administrativo.

\section{RESUMEN}

El objeto de este trabajo es delimitar y concretar el significado del término transparencia aplicado a la contratación pública y despejar las dudas que plantea el sistema de fuentes con incidencia en la materia (la ley de contratos del sector público, la legislación de transparencia de 2013 y la ley de procedimiento administrativo común), proponiendo una interpretación integrada del mismo.

El concepto de transparencia en materia de contratación pública deriva de su configuración en el derecho de la Unión Europea como principio abstracto que favorece la buena gobernanza y la participación ciudadana, y que se orienta a lograr el mercado único. Pero su plasmación a nivel interno en varias normas con rango de ley exige clarificar las obligaciones que conlleva y su régimen de control, eliminando confusiones de articulación normativa.

\section{PALABRAS CLAVE}

Transparencia; contratación pública; procedimiento administrativo.

\begin{abstract}
The purpose of this work is to define and specify the meaning of the term transparency applied to public procurement and to clear the doubts posed by the system of sources with an impact on the subject (the law of public sector contracts, the transparency legislation of 2013 and common administrative procedure law), proposing an integrated interpretation of it.

The concept of transparency in the field of public procurement came from its configuration in the law of the European Union as an abstract principle that benefits good governance and citizen participation, and which aims to achieve the single market. But its internal expression in several norms with the rank of law requires clarification of the obligations that it entails and its control regime, avoiding confusion of normative articulation.
\end{abstract}

\section{KEYWORDS}

Transparency; public procurement; administrative procedure.

\footnotetext{
1 Este trabajo se realiza en el marco del Proyecto de Investigación de Excelencia DER2017-86637-C3-2-P; financiado por el Ministerio de Ciencia, Innovación y Universidades, AEI/FEDER, UE.
} 
REALA. Nueva Época - N. 12, octubre-marzo 2019 - ISSN: 1989-8975 - DOI: 10.24965/reala.i12.10714 - [Págs. 6-25]

La transparencia como principio vertebrador de la contratación pública: significado y problemas de articulación normativa

Isabel González Ríos

\begin{abstract}
SUMARIO
1. ÁMBITO COMPETENCIAL Y ENCUADRE NORMATIVO. 2. LA TRANSPARENCIA EN LAACTIVIDAD PÚBLICA Y SU INCIDENCIA EN LA CONTRATACIÓN. 2.1. ¿QUÉ SE ENTIENDE POR «ACTIVIDAD PÚBLICA» TRANSPARENTE? 2.2. LOS CONTRATOS COMO MATERIA OBJETO DE PUBLICIDAD ACTIVA Y PASIVA. 3. EL PROCEDIMIENTO DE CONTRATACIÓN PÚBLICA Y MECANISMOS DE TRANSPARENCIA. 3.1. LA RELACIÓN ENTRE EL PROCEDIMIENTO ADMINISTRATIVO COMÚN Y EL PROCEDIMIENTO DE CONTRATACIÓN PÚBLICA: SU INCIDENCIA EN LA TRANSPARENCIA PÚBLICA. 3.2. EL SIGNIFICADO Y ALCANCE DEL PRINCIPIO DE TRANSPARENCIA EN LA CONTRATACIÓN DEL SECTOR PÚBLICO. 3.2.1. La transparencia en la contratación pública como garantía del Mercado Único. 3.2.2. La transparencia como principio vertebrador de la contratación pública en la Ley 9/2017 CSP. 4. EL CONTROL DE LA FALTA DE TRANSPARENCIA EN LA CONTRATACIÓN PÚBLICA. 5. CONSIDERACIONES FINALES. BIBLIOGRAFÍA.
\end{abstract}

\title{
1. ÁMBITO COMPETENCIAL Y ENCUADRE NORMATIVO
}

El estudio de la contratación pública transparente ${ }^{2}$ exige que, siquiera sea someramente, nos refiramos a las entidades con competencias en la materia y a su marco normativo regulador. Aunque ello requiere que nos centremos en el sector de la contratación pública, no podemos obviar otras materias relacionadas que, sin duda, vienen a condicionar el entendimiento de dicha transparencia contractual. Nos referimos a la transparencia propiamente dicha, como principio de actuación de las Administraciones públicas y entidades relacionadas, y al procedimiento administrativo como garantía para los interesados de que la Administración ajusta su actuación a la Ley, lo cual en sí mismo es la mayor muestra de transparencia en la actuación administrativa ${ }^{3}$.

En consecuencia, contratación, transparencia pública y procedimiento administrativo son las materias que enlazamos en este estudio. El papel y la intensidad regulatoria que corresponde a la Unión Europea

\footnotetext{
2 La transparencia en la contratación administrativa ha sido ampliamente abordada por la doctrina desde varias perspectivas: a) bien por su relación con la utilización de medios electrónicos (vid. COTINO HUESO, L. (2017): "La regulación del uso de medios electrónicos en la difusión activa de información pública y el ejercicio del derecho de acceso”, en MARTIN DELGADO, I. (dir.): La reforma de la administración electrónica: una oportunidad para la innovación desde el Derecho. Madrid: Instituto Nacional de Administración Pública, INAP; GALLEGO CÓRCOLES, I. (2017): "Breves notas sobre el uso de medios electrónicos en la contratación pública", en MARTíN DELGADO, I. (dir.): La reforma de la administración electrónica: una oportunidad para la innovación desde el Derecho. Madrid: Instituto Nacional de Administración Pública, INAP; MARTíN DELGADO, I. (2018): "El uso de los medios electrónicos en la contratación pública", en GIMENO FELIÚ, J. M. ${ }^{a}$ (dir.): Estudio Sistemático de la Ley de Contratos del Sector Público. Navarra: Thomson Reuters Aranzadi; b) por su importancia en la lucha contra el fraude y la corrupción (al respecto, entre otros: CERRILLO I MARTíNEZ, A. (2016): "Las compras abiertas y la prevención de la corrupción”, en Gestión y Análisis de Políticas Públicas, GAPP, núm. 15; GIMENO FELIÚ, J. M. ${ }^{2}$ (2017): "Medidas de prevención de corrupción y refuerzo de la transparencia en la contratación pública", en Revista de Estudios de la Administración Local y Autonómica, REALA. Nueva Época, núm. 7, págs. 47 y ss.; GONZÁLEZ PÉREZ, J. (2014): Corrupción, ética y moral en las Administraciones públicas. Navarra: Civitas; MARTíNEZ FERNÁNDEZ, J. M. (2016): Contratación pública y transparencia: medidas prácticas para atajar la corrupción en el marco de la nueva regulación. Las Rozas, Madrid: Wolters Kluwer. El Consultor de los Ayuntamientos; MEDIDA ARNAIZ, T. (2016): "La necesidad de reformar la legislación sobre contratación pública para luchar contra la corrupción: las obligaciones que nos llegan desde Europa”, en Revista Vasca de Administración Pública. Herri-Arduralaritzako Euskal Aldizkaria, RVAP, núm. 104-2, págs. 77-113; TOLIVAR ALAS, L. (2019): "Contratación pública: corrupción y transparencia en una sociedad digital”, en DEL GUAYO CASTIELLA, I. y FERNÁNDEZ-CARBALLAL, A. (coords.): Los desafíos del derecho público en el siglo XXI: libro conmemorativo del XXV aniversario del acceso a la Cátedra del Profesor Jaime Rodríguez-Arana Muñoz. Madrid: Instituto Nacional de Administración Pública, INAP.; y c) como derecho ciudadano y sus límites (vid. VV.AA (2017): Los límites al derecho de acceso a la información pública. Madrid: Instituto Nacional de Administración Pública, INAP; FERNÁNDEZ RAMOS, S. (2017): "La reclamación ante los órganos de garantía del derecho de acceso a la información pública”, en Revista General de Derecho Administrativo, RGDA, núm. 45; RAMS RAMOS, S. (2016): "El procedimiento de ejercicio del derecho de acceso a la información pública", en Revista General de Derecho Administrativo, RGDA, núm. 41; RAZQUIN LIZARRAGA, M. M." (2018): "El principio de confidencialidad en la contratación pública”, en GIMENO FELIÚ, J. M. ${ }^{a}$ (dir.): Estudio sistemático de la Ley de Contratos del Sector Público, págs. $867-911$. Navarra: Thomson Reuters Aranzadi.

Estudios más generales sobre la transparencia en la contratación pública son: CERRILLO I MARTíNEZ, A. (2017): Contractació oberta. [Barcelona]: Generalitat de Catalunya; IGLESIAS REY, P. (2018): "Transparencia en la contratación pública", en MESTRE DELGADO, J. F. y MANENT ALONSO, L. (dirs.) y TENHAEFF LACKSCHEWITZ, S. (coord.): La Ley de Contratos del Sector Público Ley 9/2017, de 8 de noviembre: aspectos novedosos, págs. 295-329. Valencia: Tirant lo Blanch; MALARET I GARCÍA, E. (2016): "EI nuevo reto de la contratación pública para afianzar la integridad y el control: reforzar el profesionalismo y la transparencia”, en Revista Digital de Derecho Administrativo, núm. 15, págs. 21 y ss.; MELLADO RUIZ, L. (2017): El principio de transparencia integral en la contratación del sector público. Valencia: Tirant lo Blanch.

3 La importancia de arbitrar un procedimiento administrativo en la lucha contra el fraude ha sido puesto de manifiesto por FUERTES LÓPEZ, M. (2014): "La necesidad de un procedimiento para combatir el fraude. (A propósito de la Oficina Europea de Lucha contra el fraude, OLAF)", en Revista de Administración Pública, RAP, núm. 195, págs. 269 y ss.
} 
(UE), al Estado y a las Comunidades autónomas en las mismas (CCAA) difiere según su ámbito de competencias. Así, la UE realiza una regulación directa de la contratación pública, mientras que la transparencia y los procedimientos administrativos los aborda de manera sectorial. A nivel comunitario la contratación se configura como elemento transversal para la satisfacción de las diferentes políticas con las que se pretende alcanzar el mercado único europeo, a través -como indica el art. 26 TFUE- de la libre circulación de mercancías, personas, servicios y capitales. Para ello se hacen necesarias «medidas relativas a la aproximación de las disposiciones legales, reglamentarias y administrativas de los Estados miembros...» (Art. 114 TFUE). Este es el fundamento normativo para que la UE haya dictado la vigente normativa de contratación pública. A nivel interno, la Constitución Española de 1978 (CE) dispone que el Estado tiene competencia exclusiva para dictar la legislación básica en materia de contratación pública. Esta atribución de competencia ha llevado a todas las Comunidades Autónomas (CCAA) a asumir en sus correspondientes Estatutos de Autonomía las competencias de desarrollo legislativo y ejecución de la legislación básica del Estado (Gamero y Fernández, 2018: 802; Sánchez, 2017:596).

Por lo que respecta a la transparencia pública, el TFUE la configura como un principio, al que también denomina "principio de apertura», de actuación de los órganos, organismos y entidades de la UE, el cual deriva del principio de «buena gobernanza» y del «principio de participación ciudadana» (art. 15, apartado $1 .^{\circ}$, del TFUE). Más específicamente, este principio se manifiesta en la publicidad de las sesiones del Parlamento, en el derecho de acceso a los documentos de la UE, en la transparencia de sus trabajos (apartados $2 .^{\circ}$ y $3 .^{\circ}$ del art. 15); y en una amplia participación ciudadana, que encuentra su cauce en la posibilidad de expresar su opinión en todos los ámbitos de actuación de la UE y a través de consultas públicas a las partes interesadas (art. 11 del Tratado de la UE). Por su parte, a nivel interno, la falta de un reconocimiento expreso de la transparencia en la Constitución Española (CE) como materia objeto de distribución de competencias no ha impedido al Estado su regulación con apoyo en títulos competenciales como "[L]a regulación de las condiciones básicas que garanticen la igualdad de todos los españoles en el ejercicio de los derechos y en el cumplimiento de los deberes constitucionales" (art. 149.1.1), "[B]ases y coordinación de la planificación general de la actividad económica" (art. 149.1.13) y "[L]as bases del régimen jurídico de las Administraciones públicas" (art. 149.1.18), como ha analizado Velasco Rico (Velasco, 2014) ${ }^{4}$. Ello no es óbice para que aspectos de esa transparencia pública como «el acceso a la información pública» encuentre su encaje constitucional en el art. 105 b) (acceso a los archivos y registros) o-como ha sostenido Fernández Ramos y Piñar Mañas- en los derechos informativos del art. 20 de la $\mathrm{CE}^{5}$.

Íntimamente relacionada con la materia «transparencia pública» se encuentra el procedimiento administrativo -como tempranamente pusiera de manifiesto Rodríguez Arana (Arana, 1995:447 y ss), como si del núcleo duro de la misma se tratara, por cuanto permite la participación ciudadana en los asuntos públicos y la realización del principio de contradicción. En esta materia el Parlamento Europeo viene impulsando la elaboración de una Ley de Procedimiento Administrativo en la UE, que hasta el momento no ha sido bien acogida por la Comisión Europea ${ }^{6}$; por lo que a falta de ese procedimiento administrativo común comunitario, ampliamente reclamado por la doctrina (Agudo, 2013:61; Barnés, 1993; Martin, 2010:99; Fuertes, 2012; Parejo y Vaquer, 2018; Parejo, 2000:229), hemos de acudir a los distintos procedimientos que la UE regula en las materias en las que ostenta competencias. A nivel interno, el art. 149.1.18 CE atribuye al Estado competencia exclusiva

\footnotetext{
4 Véase la Disposición Final Octava de la Ley 19/2013, de 9 de diciembre, de Transparencia, acceso a la información pública y buen gobierno, que fundamenta su publicación en dichos títulos competenciales.

5 FERNÁNDEZ RAMOS, S. (2018): “La transparencia pública: pasado, presente y futuro", en Revista Aragonesa de Administración Pública, RArAP, núm. 51, págs. 213-243; PIÑAR MAÑAS, J. L. (2014): "Transparencia y derecho de acceso a la información pública: algunas reflexiones en torno al derecho de acceso en la Ley 19/2013 de Transparencia, acceso a la información pública y buen gobierno", en Revista Catalana de Dret Public, núm. 49, págs. 5 y 7, considera este derecho imprescindible para la construcción de una sociedad democrática y participativa.

6 Para ello aprobó una primera Resolución, de 15 de enero de 2013, con recomendaciones a la Comisión Europea, en la que le pide que presente una propuesta de Reglamento sobre la Ley de Procedimiento Administrativo de la UE, acompañando una serie de propuestas como Anexo. A dicha Resolución le siguió la Resolución de 9 de junio de 2016, para una Administración de la UE abierta, eficiente e independiente, en la que pide de nuevo a la Comisión que elabore una propuesta legislativa para su inclusión en su programa de trabajo del año 2017. Ambas Resoluciones pueden consultarse en: https://eur-lex.europa.eu/legal-content/ES/ALL/?uri=CELEX\%3A52013IP0004. http://www.europarl.europa.eu/sides/getDoc.do?pubRef=-//EP//TEXT+TA+P8-TA-2016-0279+0+DOC+XML+V0//ES.

La respuesta oficial de la Comisión Europea a esta Resolución ha sido su falta de convencimiento sobre la necesidad de aprobar un único instrumento legal en materia de procedimiento, considerando que la propuesta del Parlamento no estaba «suficientemente respaldada por un análisis de evaluación de impacto y de coste-beneficio». Ante esta situación el Parlamento solicitó un estudio para evaluar el posible impacto de la propuesta.
} 
para la regulación del procedimiento administrativo común, lo que no ha estado exento de debate doctrinal por su confusión en parte con las «bases del régimen jurídico de las Administraciones públicas» (Baño, 2015; Martín Retortillo, 1993: 7; Martín Rebollo, 2015: 2; Díez, 2017: 484; Huergo, 2015; Gamero, 2017:171). Como aportación destacada, el profesor López Menudo (2016: 21) viene sosteniendo que el Estado debe considerar común toda garantía esencial, ya se encuentre en un procedimiento administrativo general o especial, sea de competencia sustantiva o autonómica. Al respecto el Tribunal Constitucional ha clarificado que el Estado ostenta una competencia plena y exclusiva sobre el procedimiento administrativo común, sin perjuicio de que las CCAA puedan regular procedimientos especiales en materias en las que tengan competencias legislativas, aunque estos procedimientos deben respetar en todo caso las reglas de procedimiento establecidas en la legislación del Estado (STC 227/1988, STC 23/1993; STC 166/2014; 33/2018 y 55/2018, entre otras) ${ }^{7}$.

Con base en esta distribución multinivel de competencias, el bloque normativo más directamente relacionado con la transparencia en la contratación pública lo integra la normativa sobre contratación pública, la relativa a la transparencia pública y la que contiene el régimen jurídico de las Administraciones públicas y el procedimiento administrativo común. El vigente marco normativo de la contratación pública en España lo integran las Directivas 2014/23/UE, 2014/24/UE, 2014/25/UE; 2014/55/UE (Fernández y Valcárcel, 2014; Gimeno, 2013:39; Medina, 2016:77; Razquin, 2015:97) ${ }^{8}$. Los postulados de estas Directivas han sido transpuestos al derecho interno a través de la Ley 9/2017 de Contratos del Sector Público (en adelante Ley 9/2017 CSP) ${ }^{9}$, sin que se haya aún incorporado la Directiva 2014/25/UE, a pesar de contar con legislación interna en esta materia. Este relevante bloque normativo sobre contratación pública no es ajeno al principio de transparencia, que debe regir la adjudicación del contrato y que debe ser respetado en aquellos contratos de elevada cuantía para garantizar su conocimiento fuera de las fronteras nacionales, a nivel comunitario. Este es el significado que impregna la normativa española, con la que además se tratan de atajar otros problemas como la corrupción ligada al empleo de fondos públicos en la contratación.

A nivel interno, y con el objetivo de integrar la transparencia en la actividad de todas aquellas entidades que manejan fondos públicos, por tanto, con una regulación muy pegada a objetivos de control presupuestario, pero también con el objeto de visibilizar la actuación pública y favorecer un mejor conocimiento de cómo actúa el poder público, se ha aprobado la Ley 19/2013, de Transparencia, acceso a la información pública y buen gobierno (en adelante Ley 19/2013 TBG) ${ }^{10}$. Esta norma viene a «ampliar y reforzar la transparencia en la actividad pública» (art. 1) y lo hace a través de la regulación de la publicidad activa, del derecho al acceso a la información pública y exigiendo dicha transparencia en la actuación de los miembros del Gobierno y Altos cargos ${ }^{11}$. Posteriormente, ha sido la Ley 40/2015 de Régimen Jurídico del Sector Público (en adelante Ley 40/2015 RJSP) ${ }^{12}$ la que consagra el principio de transparencia en la actuación administrativa (art. 3.1.c); y lo hace asumiendo el contenido del art. 103 de la CE que dispone que las Administraciones públicas sirven con objetividad los intereses generales y actúan de acuerdo, entre otros, con el principio de eficacia. Eficacia en la actuación de la administración pública que no sería reconocible sin una actuación transparente. Indisolublemente unida a la citada Ley, se aprueba Ley 39/2015 de Procedimiento Administrativo Común de las Administraciones públicas (en adelante Ley 39/2015 PACAP) ${ }^{13}$, que no solo afecta a la transparencia por las

7 STC núm. 227/88, de 29 de noviembre (Pte. D. Jesús Leguina villa, FJ. 32. ${ }^{\circ}$ ); STC núm. 23/93, de 21 de enero (Pte. D. Miguel Rodríguez Piñero, FJ. 3. ${ }^{\circ}$ ); STC núm. 166/2014, de 22 de octubre (Pte. D. Ricardo Enriquez Sancho, FJ. 5..$^{\circ}$; STC núm. 33/2018, de 12 de abril (Pte. D. Ricardo Enríquez Sancho, FJ. 5), b); y STC núm. 55/2018, de 24 de mayo (Pte. D. Andrés Ollero Tassara).

8 Directiva 2014/23/UE, del Parlamento y del Consejo, de 26 de febrero, relativa a la adjudicación de contratos de concesión; Directiva 2014/24/UE, del Parlamento Europeo y del Consejo, de 26 de febrero, sobre Contratación pública y por la que se deroga la Directiva 2004/18/CE; Directiva 2014/25/UE, de 26 de febrero, relativa a la contratación por entidades que operan en los sectores del agua, la energía, los transportes y los servicios postales; y Directiva 29014/55/UE, del Parlamento Europeo y del Consejo, de 16 de abril, relativa a la facturación electrónica en la contratación pública.

9 Ley 9/2017, de 8 de noviembre, de Contratos del Sector Público. Nuestro marco normativo interno se completa con el Real Decreto 817/2009, de 8 de mayo, que desarrollaba parcialmente la Ley 30/2007, de 30 de octubre de Contratos del Sector Público, la cual fue derogada por el Real Decreto Legislativo 3/2011, de 14 de noviembre, por el que se aprobó el Texto Refundido de la Ley de Contratos del Sector Público, hoy derogado por la vigente Ley 9/2017. Además, en lo que no contradiga la vigente Ley se aplica el Real Decreto 1098/2001, de 12 de octubre, Reglamento General de la Ley de Contratos de las Administraciones públicas (disposición que desarrollaba la Ley 13/1995, de 18 de mayo, de Contratos de las Administraciones Públicas).

10 Ley 19/2013, de 9 de diciembre, de Transparencia, acceso a la información pública y buen gobierno.

11 La mayoría de las Comunidades Autónomas cuentan con su propia legislación sobre Transparencia pública (Andalucía, Madrid, Cataluña, Comunidad Valenciana, Galicia, Castilla y León, Castilla La Mancha, Extremadura, Canarias, La Rioja, Aragón, Cantabria, Murcia, Navarra y Asturias).

12 Ley 40/2015, de 1 de octubre, de Régimen Jurídico del Sector Público.

13 Ley 39/2015, de 1 de octubre, de Procedimiento Administrativo Común de las Administraciones pública. 
expresas remisiones que realiza a la Ley 19/2013 TBG ${ }^{14}$, sino porque el procedimiento administrativo común -imbuido de las exigencias de tramitación electrónica- al proyectarse sobre los procedimientos administrativos especiales ratione materia es un mecanismo clave para la transmisión de la transparencia a todas las Administraciones públicas, ámbito subjetivo neurálgico del desarrollo de la transparencia.

De este último bloque normativo, que de forma directa o tangencialmente aborda la transparencia pública nos interesa resaltar su incidencia en el ámbito de la contratación pública. Para ello vamos a analizar cómo se configura la transparencia pública en la legislación de transparencia y su relación con la legislación de contratos del sector público. A continuación abordaremos la problemática relativa a la relación entre la legislación de procedimiento administrativo común, en la que se recogen importantes aspectos referidos a la transparencia administrativa, y la legislación de contratos del sector público; para acabar determinando el significado y alcance de la transparencia pública en esta última y los efectos que derivan de su incumplimiento.

\section{LA TRANSPARENCIA EN LA ACTIVIDAD PÚBLICA Y SU INCIDENCIA EN LA CONTRATACIÓN}

\section{1. ¿Qué se entiende por «actividad pública» transparente?}

Para abordar el principio de transparencia en la actividad pública se debe previamente determinar qué se entiende por «actividad pública», de tal manera que podamos indicar si en la misma se incluye la contratación pública; y a renglón seguido concretar cuál es el contenido de esa transparencia. Al respecto, hemos de partir de la normativa específica reguladora de esta materia, la Ley 19/2013 de Transparencia, acceso a la información pública y buen gobierno -abordada con profusión por la doctrina (Guichot, 2016:89 y 2014; Fernández y Pérez, 2017; Rodríguez y Sendín, 2014, Troncoso, 2017; Valero y Fernández, 2014), sin que proceda en este momento profundizar en la normativa autonómica.

Si realizamos una interpretación sistemática de la Ley 19/2013 TBG, cuyo Título I se intitula "Transparencia de la actividad pública", refiriéndose los arts. 2 y 3 al ámbito subjetivo de aplicación, hemos de concluir afirmando que esa "actividad pública», y consecuentemente la transparencia pública, se extiende más allá del estricto ámbito de las Administraciones públicas ${ }^{15}$, siendo aquella exigible a instituciones constitucionales y autonómicas, así como a entidades de naturaleza privada. De «amplio y complejo» ha calificado Barrero Rodríguez dicho ámbito subjetivo (Barrero, 2016:241; 2014, 63 y ss); que al incluir a entes privados haría más oportuno que dicho Título I aludiera a "Transparencia de la actividad de interés público". Pero al margen de los citados sujetos, ¿cabe exigir transparencia al Gobierno y a los altos cargos; a las autoridades propiamente dichas? Su exclusión del Título I de la Ley 19/2013 TBG no significa que no deban cumplir las exigencias de transparencia. Lo que ocurre es que en este caso el legislador prefiere hablar de «buen gobierno», en sentido más amplio, teniendo en cuenta sus funciones de dirección de la Administración pública ${ }^{16}$. Así, el buen gobierno es exigible a los miembros del Gobierno, Secretarios de Estado y resto de altos cargos de la Administración General del Estado y entidades vinculadas o dependientes de aquella, así como a los altos cargos o asimilados de las Comunidades autónomas o entes locales (art. 25). Ese «buen gobierno» se asocia a una serie de principios de actuación entre los que se sitúa «la transparencia en la gestión de los asuntos públicos» (art. 26).

Partiendo de ese concepto amplio de actividad pública, ¿cuál es el contenido de la transparencia pública? La Ley 19/2013 TBG lo identifica con dos aspectos: a) la publicidad activa, que se refiere a la publicación de forma periódica y actualizada de la información que resulte relevante sobre la actuación pública de que se trate (art. 5.1); y b) el derecho de acceso a la información pública (Barrero, 2016:245), o sea, a los contenidos o documentos que obren en poder de los sujetos a los que se aplica esta ley ${ }^{17}$, y que hayan sido elaborados

14 Véanse los arts. 13 d) y 71 de la Ley 39/2015, de Procedimiento Administrativo Común de las Administraciones públicas que regulan respectivamente el derecho de acceso a la información pública, a los archivos y registros, que es manifestación del principio de transparencia; y el impulso de oficio de los procedimientos respetando el principio de transparencia y publicidad. Al mismo tiempo, los arts. 129 y 132 son manifestación del principio de transparencia en la elaboración y aprobación normativa.

15 El art. 2.2 de la LTBG las circunscribe a las Administraciones territoriales, Administraciones institucionales e independientes y Universidades.

16 A la transparencia como elemento clave del buen gobierno y las «virtudes» que derivan de la misma se ha referido acertadamente FERNÁNDEZ RAMOS, S. (2018): "La transparencia pública: pasado, presente y futuro”, op. cit, págs. 223 y ss. Sobre los códigos de buen gobierno aplicables a los cargos políticos y altos cargos, por todos, véase: PRIETO ROMERO, C. (2011): "Medidas de transparencia y ética pública: los códigos éticos, de conducta o buen gobierno”, en Anuario de Gobierno Local, núm. 1, págs. 315-347.

17 Excluidos los partidos políticos, organizaciones sindicales y empresariales y entidades beneficiarias de ayudas públicas, como se deduce del art. 2.1 y a sensu contrario del art. 3 . 
o adquiridos en el ejercicio de sus funciones (arts.12 y 13) ${ }^{18}$. Por su parte, el contenido de la transparencia en la actuación del Gobierno y altos cargos queda algo indefinido en la LTBG que solo establece que "[A] ctuarán con transparencia en la gestión de los asuntos públicos, de acuerdo con los principios de eficacia, economía y eficiencia y con el objetivo de satisfacer el interés general" y que "[D]esempeñarán sus funciones con transparencia" (art. 26.2.a) 1. ${ }^{\circ}$, b) $7 .^{\circ}$ ), sin clarificar los concretos parámetros a través de los cuales garantizarán una actuación transparente y sin que la misma venga representada por la publicidad activa o el derecho de acceso a la información pública.

De ello se deduce que la transparencia pública va referida a la actividad «pública» (pública y en algunos casos privada), más allá del sujeto "Administración pública», tanto cuando no existe relación directa con el ciudadano, o sea, a través de la mera publicidad de aquella actuación, como cuando deriva de una relación con el mismo, mediante el derecho de acceso a la información pública. Y por otro lado, esa transparencia se predica, aunque de forma más indeterminada, de la actuación del Gobierno y de los altos cargos.

\subsection{Los contratos como materia objeto de publicidad activa y pasiva}

La Ley 19/2013 TBG reconoce la existencia al momento de su publicación de normas sectoriales que inciden en la transparencia pública, como la relativa a la contratación pública, a las subvenciones, a los altos cargos, entre otras ${ }^{19}$. Pero no se trata en este momento de analizar cómo se configura la transparencia pública en la legislación de contratación del sector público, sino de abordar si las exigencias de transparencia pública que derivan de la Ley 19/2013 TBG (y, en su caso, de la correspondiente normativa autonómica en la materia) son aplicables respecto de la actividad contractual pública.

Para ello debemos atender al ámbito de aplicación de esta Ley 19/2013 TBG, comparándolo con los sujetos obligados por la Ley 9/2017 CSP, y a lo dispuesto en la Disposición Adicional Primera de la Ley 19/2013 TBG. Atendiendo al ámbito subjetivo de aplicación de la legislación de transparencia pública, y comparándolo con lo previsto en el art. 3 de la Ley 9/2917 CSP, observamos una importante coincidencia entre las Administraciones, organismos y entidades sujetos a ambas normativas. ¿Supone eso que el sector público cuando realiza la actividad contractual debe respetar las obligaciones de «publicidad activa» y de «acceso a la información pública» que establece la Ley 19/2013 TBG? La respuesta debe ser positiva, con algunas puntualizaciones.

En primer lugar, en materia de publicidad activa, todas las entidades que se sitúan en el ámbito de aplicación de la Ley 19/2013 TBG tienen obligaciones genéricas de publicidad sobre su actuación ${ }^{20}$ y obligaciones específicas respecto a contratación pública. En este último ámbito material, el art. 8.1.a) recoge la obligación de hacer públicos «todos los contratos» ${ }^{21}$, «las decisiones de desistimiento y renuncia de los contratos» y «datos estadísticos sobre el porcentaje en volumen presupuestario de contratos adjudicados a través de cada uno de los procedimientos previstos en la legislación de contratos del sector público»; estas exigencias son aplicables a todos los sujetos que el art. 2 de la Ley 19/2013 TBG recoge en su ámbito de aplicación ${ }^{22}$.

La obligación de dar publicidad a los contratos, como parte de la publicidad activa, se hace extensible a los partidos políticos, organizaciones sindicales y empresariales y entidades privadas que perciban en

18 Hemos de tener en cuenta que la propia Ley 19/2013 TBG en su Disposición Adicional Primera remite a la normativa reguladora del concreto procedimiento cuando sean los interesados los que quieran acceder a los documentos del procedimiento que se está tramitando. Al mismo tiempo, aquellas materias que tengan un régimen específico de acceso a la información se regirán por su normativa específica y supletoriamente por la Ley 19/2013 de TBG.

19 Exposición de motivos de la Ley 19/2013, de 9 de Transparencia, acceso a la información pública y buen gobierno.

20 Así lo recogen los arts. 6 a 8 de la Ley 19/2013 TBG, que establecen la obligación de publicar información sobre sus funciones, normativa aplicable y estructura organizativa; de que las Administraciones públicas publiquen además sus planes y programas anuales y plurianuales, su desarrollo y resultados, así como, información con relevancia jurídica; publicar información económica, presupuestaria y estadística.

21 Pormenoriza este artículo los datos a publicar: el objeto, duración, importe de la licitación y de la adjudicación, el procedimiento utilizado para su celebración, los instrumentos a través de los que, en su caso, se ha publicitado, el número de licitadores que han participado, la identidad del adjudicatario y las modificaciones del contrato.

22 Para facilitar esta exigencia de publicidad activa relativa a la contratación pública, se impone a los adjudicatarios de contratos del sector público la obligación de suministrar toda la información que resulte necesaria, en los términos previstos en el respectivo contrato (art. 4 Ley 19/2013 TBG). Esta imposición muestra la necesidad de incluir una cláusula en el contrato para dar cumplimiento a esta exigencia legal, si bien es cierto que si tenemos en cuenta los datos que deben públicarse (objeto del contrato, duración, importe...), todos ellos han de ser conocidos por la Administración Pública, haciéndose superflua aquella «obligación de suministrar información» por parte de los adjudicatarios, salvo quizás en lo relativo a «las modificaciones del contrato». 
REALA. Nueva Época - N. ${ }^{12}$, octubre-marzo 2019 - ISSN: 1989-8975 - DOI: 10.24965/reala.i12.10714 - [Págs. 6-25]

La transparencia como principio vertebrador de la contratación pública: significado y problemas de articulación normativa

Isabel González Ríos

el periodo de un año subvenciones o ayudas en cantidad superior a 100.000 euros o cuando al menos el $40 \%$ del total de sus ingresos tengan el carácter de ayuda o subvención pública, y alcancen como mínimo la cantidad de 5.000 euros, "cuando se trate de contratos o convenios celebrados con una Administración Pública» (art. 8.2 Ley 19/2013 de TBG).

Para dar cumplimiento a la obligación de publicidad activa, se requiere del correspondiente soporte. El art. 5.4 de la Ley 19/2013 TBG establece que dicha publicidad se hará efectiva en las correspondientes sedes electrónicas, y de manera clara, estructurada y entendible ${ }^{23}$.

En segundo lugar, en lo que se refiere a la transparencia pública a través del derecho de acceso de cualquier persona a los contenidos o documentos (información pública) que obren en poder de los sujetos a los que resulta de aplicación la Ley 19/2013 TBG, que tiene su fundamento constitucional en el derecho de acceso de los ciudadanos a los archivos y registros administrativos (art. 105, apdo. b) ${ }^{24}$, y al específico procedimiento de acceso que se recoge en dicha ley ${ }^{25}$, hay que tener en cuenta las dos previsiones que se contienen en la Disposición Adicional Primera, de la que derivan dudas de articulación normativa (Piñar, 2014:9): a) la aplicación supletoria de la Ley 19/2013 TBG en aquellas materias que cuenten con una normativa específica de acceso a la información ${ }^{26}$; y b) «la normativa reguladora del correspondiente procedimiento administrativo será la aplicable al acceso por parte de quienes tengan la condición de interesados en el procedimiento en curso a los documentos que se integren en el mismo».

En lo que respecta a la aplicación supletoria de la Ley ${ }^{27}$, cabe plantearse qué ocurre si se aprueba una norma autonómica en sentido divergente a lo previsto en la Ley 19/2013 TBG. En tal caso entendemos que hemos de estar a los títulos competenciales en los que se fundamenta la aprobación de la Ley 19/2013 TBG, entre los que se encuentra el art. 149.1.18 CE, para sostener que no cabe que la legislación autonómica contradiga lo dispuesto en esta norma en cuanto al procedimiento de acceso a la información pública. Y ello, máxime cuando el art. 13.d) de la Ley 39/2015 PACAP se remite a la Ley 19/2013 TBG en cuanto al derecho de acceso a la información, a los archivos y registros, en una suerte de configuración como procedimiento administrativo común. En esta línea, aunque limitándolo a un aspecto concreto de ese procedimiento de acceso a la información pública, la producción del silencio administrativo, se ha pronunciado la STC $104 / 2018^{28}$. En esta sentencia el Alto Tribunal sostiene que el silencio negativo en resoluciones presuntas de solicitudes de acceso a aquella información que establece la Ley 19/2013 «cumple una función típica de las normas de "procedimiento administrativo común"»: garantizar un tratamiento común de los administrados ante todas las Administraciones públicas". De ahí que considere que se produce la inconstitucionalidad mediata de una ley autonómica que establecía el silencio positivo en tal tipo de procedimientos. Otra cuestión relevante en cuanto a la aplicación supletoria de la Ley 19/2013 TBG es si la regulación contenida en la Ley 9/2017 CSP puede considerarse como normativa específica en materia de acceso a la información

23 Para facilitar el acceso a toda esa información la Administración General del Estado, en aplicación del art. 10 de la Ley $19 / 2013$ TBG, ha desarrollado el Portal de Transparencia, dependiente del Ministerio de la Presidencia, que contiene información relativa a su ámbito de actuación, disponible en: https://transparencia.gob.es/.

Como complemento a este Portal de Transparencia en el que podemos encontrar información sobre contratos públicos, el art. 347 de la Ley 9/2017 CSP regula la Plataforma de Contratos del Sector Público, de carácter electrónico, que permite la difusión de los perfiles del contratante de los órganos del sector público; en línea: https://contrataciondelestado.es/wps/portal/perfilContratante.

${ }^{24}$ A la vinculación a esta previsión constitucional y no al derecho fundamental a recibir información del art. 20.1.d) de la CE, se refiere CARRILLO, M. (2015): "Transparencia y derechos de acceso a la información en las Administraciones Públicas", en Parlamento y Constitución: anuario, núm. 17, pág. 275.

25 Respecto a la relación entre el procedimiento de acceso a la información pública y el procedimiento administrativo común, hay que destacar que el art. 13.d) de la Ley 39/2015 PACAP remite a la Ley 19/2013 TBG la regulación del derecho de acceso a la información pública, a los archivos y registros.

Sobre el citado procedimiento de acceso, vid. MESEGUER YEBRA, J. (2014): "El procedimiento administrativo para el acceso a la información pública”, en Revista Jurídica de Castilla y León, núm. 33, págs. 1-34.

26 Sobre los riesgos de vaciamiento del contenido de la Ley 19/2013 TBG en cuanto al derecho de acceso a la información pública, dado su carácter supletorio ante disposiciones específicas, han alertado autores como FERNÁNDEZ RAMOS, S. (2013): "El acceso a la información en el Proyecto de Ley de transparencia, acceso a la información pública y buen gobierno", en Revista Aragonesa de Administración Pública, RArAP, núm. 14, pág. 238; GUICHOT REINA, E. (2014): "Transparencia: aspectos generales", en GUICHOT REINA, E. (coord.): Transparencia, acceso a la información pública y buen gobierno: estudio de la Ley 19/2013, de 9 de diciembre. Madrid: Tecnos. pág. 55; CASADO CASADO, L. (2014): "Estudio sobre el alcance de la supletoriedad de la Ley 19/2013, de 9 de diciembre, de Transparencia, acceso a la información pública y buen gobierno sobre la Ley 27/2006, de 18 de julio, Reguladora del derecho de acceso a la información ambiental", en Revista Vasca de Administración Pública. Herri-Arduralaritzako Euskal Aldizkaria, RVAP, núm. 99-100, págs. 823-824.

27 Entendemos que hay que referir esa supletoriedad respecto a leyes estatales especiales.

28 STC 104/2018, de 4 de octubre (Pte. J. José González Rivas, FJ. 5. ${ }^{\circ}$ ). 
contractual. Al respecto, el Consejo estatal de Transparencia y Buen Gobierno ha fijado un criterio interpretativo restrictivo respecto a dicha aplicación supletoria, exigiendo una regulación específica y detallada del acceso a la información ${ }^{29}$. En esta línea, varios Consejos autonómicos de transparencia han afirmado que la legislación de contratos del sector público no establece un régimen específico de acceso a la información pública que desplace al régimen general de la Ley 19/2013 TBG ${ }^{30}$. En esta línea, el art. 346, apartado 5. de la Ley 9/2017 CSP dispone que el acceso público a los datos que no tengan el carácter de confidencial y que no hayan sido previamente publicados de modo electrónico o a través de internet se facilitarán de conformidad con lo dispuesto en la Ley 19/2913 TBG. De lo que se deduce que el legislador en materia de contratos se remite en cuanto al acceso a la información contractual al régimen previsto en la legislación de transparencia pública.

Respecto al derecho de acceso como interesados en el procedimiento, por lo que ahora nos interesa, supone que cuando se esté tramitando un procedimiento de contratación pública, el acceso de quienes ostentan la condición de interesados en el mismo a los documentos del expediente de contratación se rige por lo dispuesto en la Ley 9/2017 CSP ${ }^{31}$.

Del carácter básico de la Ley 19/2013 TBG, de las interpretaciones que vienen realizando el Consejo estatal de Transparencia y Buen Gobierno y los Consejos autonómicos podemos concluir que las solicitudes de acceso a la información pública se rigen por la Ley 19/2013 TBG, sin que sea de aplicación prioritaria la legislación de procedimiento administrativo común ni ninguna otra; salvo en el caso de que la materia sobre la que versa la solicitud esté regulada en normativa específica en materia de acceso, según lo dispuesto en la Disposición Adicional Primera y tal como la ha interpretado el Consejo, y salvo procedimientos en curso, en cuyo caso si se es interesado se aplica la norma reguladora del concreto procedimiento ${ }^{32}$.

A continuación nos referimos a la relación y prevalencias aplicativas que se producen entre la Ley 39/2015 PACAP y la Ley 9/2017 CSP, lo que tiene especial interés en el acceso a la información contractual, como parte de la transparencia pública, y por los aspectos procedimentales que regulan ambas normas y que resultan elemento esencial en dicha transparencia.

\section{EL PROCEDIMIENTO DE CONTRATACIÓN PÚBLICA Y MECANISMOS DE TRANSPARENCIA}

Antes de analizar los elementos de transparencia pública recogidos en la Ley 9/2017 CSP, procede que aclaremos la relación que esta normativa mantiene con la Ley 39/2015 PACAP. Y ello máxime cuando la propia Ley 19/2013 TBG remite a la concreta normativa procedimental la regulación del acceso a la información por parte de los interesados en los procedimientos administrativos que se estén tramitando (Disposición Adicional Primera); a la vez que la Ley 9/2017 CSP dispone que los procedimientos regulados en esta ley se rigen por lo dispuesto en ella y subsidiariamente por la Ley 39/2015 PACAP (Disposición Final Cuarta). En consecuencia, ¿resultan aplicables en materia de contratación pública las previsiones sobre transparencia

29 Criterio interpretativo 008/2015, de 12 de noviembre de 2015 del Consejo estatal de Transparencia y Buen Gobierno, según el cual el régimen de acceso a la información pública que recoge la Ley 19/2013 TBG se aplicará supletoriamente solo en el caso de que una norma concreta establezca un régimen específico, regulando aspectos tales como las características de la información que se solicita, los legitimados para acceder a la misma, las condiciones de acceso, etc.

Con más detalle se ha referido el Consejo en su Resolución de 25 de septiembre de 2017 (R/0309/2017), en la que exige que la regulación específica del acceso a la información pública prevea aspectos como: la forma de solicitar información, contenidos accesibles, personas legitimadas, plazos, límites legales, tramitación y forma de facilitar el acceso, resolución, recursos administrativos y, en general, cualquiera otra que ayude a configurar un procedimiento de acceso específico a la información en la materia. En el caso concreto, relativo a contratación pública, concluye que la regulación contenida en los pliegos de cláusulas particulares del contrato, que se remiten a una Instrucción administrativa que contenía las normas pertinentes de la legislación de contratos del sector público, no constituyen una verdadera regulación específica del derecho de acceso a la información, no resultando la Ley 19/2013 TBG de aplicación supletoria respecto de la normativa contractual.

30 En este sentido se han pronunciado la Resolución de 12/09/2016 del Consejo de Transparencia de Aragón y la Resolución de 8-09-2017 de la Comisión de Garantía del derecho de acceso a la información pública de Cataluña.

31 El Consejo estatal de Transparencia y Buen Gobierno viene sosteniendo que en aplicación de lo dispuesto en la Disposición Adicional Primera de la Ley 19/2013 TBG, si el acceso a la información se solicita por un interesado en el curso de un procedimiento, dicho acceso se rige por la normativa reguladora del correspondiente procedimiento; en consecuencia, no es posible la aplicación de la Ley 19/2013 TBG (entre otras, las reclamaciones RT/496/2017, de 6 de noviembre; RT/ 448/2017, de 4 de diciembre; RT/496/2017, de 23 de marzo; RT/0134/2018, de 3 de abril).

32 Así lo ha establecido, respecto a la información pública contenida en expedientes administrativos, la Resolución del Consejo estatal de Transparencia y Buen Gobierno de 19 de enero de 2016 (RT/0219/2016). 
REALA. Nueva Época - N. 12, octubre-marzo 2019 - ISSN: 1989-8975 - DOI: 10.24965/reala.i12.10714 - [Págs. 6-25]

La transparencia como principio vertebrador de la contratación pública: significado y problemas de articulación normativa

Isabel González Ríos

administrativa (relacionadas con el derecho de acceso a archivos y registros; sobre utilización de medios electrónicos...), e incluso el propio procedimiento administrativo común -como garantía de transparencia en la actuación administrativa- de la Ley 39/2015 PACAP?

\subsection{La relación entre el procedimiento administrativo común y el procedimiento de contratación pública: su incidencia en la transparencia pública}

El Tribunal Constitucional ha elaborado una doctrina jurisprudencial sobre la distribución de competencias en materia de procedimiento administrativo común y respecto a los principios y normas que definen dicho procedimiento (González, 2018:146). Esta doctrina jurisprudencial permite clarificar la relación que existe entre el procedimiento administrativo común y el procedimiento de contratación pública. Se trata de situarnos en la normativa correcta a la hora de determinar el contenido y los efectos que derivan del principio de transparencia pública en materia de contratación. Al respecto hemos de partir de la pionera STC $227 / 1988^{33}$-doctrina ampliamente reiterada y pormenorizada en posteriores sentencias (SSTC 175/2003, $132 / 2013,166 / 2014,33 / 2018$ y 55/2018) $)^{34}$ - en la que se reconoce la competencia exclusiva del Estado para regular el procedimiento administrativo común ex art. 149.1.18 CE, al tiempo que admite que las Comunidades autónomas (CCAA) tienen competencia sobre procedimiento administrativo en aquellas materias en las que ostenten competencia legislativa por razón de la materia, debiendo en todo caso respetar las reglas de procedimiento administrativo común que marque el Estado.

Pero, ¿cuál es el contenido, cuáles son los trámites que conforman el procedimiento administrativo común? El Tribunal Constitucional viene sosteniendo que el contenido del procedimiento administrativo común lo integran los principios o normas que: a) definen la estructura general del procedimiento que debe seguir la Administración en su actuación; y especialmente el establecimiento de un plazo máximo de resolución, las consecuencias de su incumplimiento y el cómputo de dicho plazo; y b) que determinan la forma de elaboración, la validez y eficacia, los modos de revisión y los medios de ejecución de los actos administrativos; y las garantías de los interesados en el procedimiento administrativo (entre otras, SSTC $130 / 2013^{35}$ y $166 / 2014^{36}$ ).

Al mismo tiempo, el Estado ostenta competencias respecto a procedimientos especiales por razón de la materia, que pueden calificarse como «comunes» (Gamero, 2017:171), pues resultan aplicables a todas las Comunidades autónomas y resto de Administraciones públicas. Así, el Tribunal Constitucional sostiene que el hecho de ostentar una competencia más específica por razón de la materia, que la competencia sobre procedimiento administrativo común, habilita al Estado para aprobar procedimientos con una regulación propia y específica (sería el caso de los procedimientos de contratación o expropiación forzosa (STC 55/2018) ${ }^{37}$. Al mismo tiempo, cuando al Estado le corresponde una competencia sustantiva básica, la misma también se ha considerado por el Alto Tribunal que le permite intervenir en procedimientos administrativos especiales, con ciertas limitaciones ${ }^{38}$.

33 STC núm. 222/88, de 29 de noviembre (Pte. D. Jesús Leguina villa, FJ. 32. ${ }^{\circ}$ ).

34 STC núm. 175/2003, de 30 de septiembre (Pte. D. Eugeni Gay Moltalvo, FJ. 10. ${ }^{\circ}$ ); STC núm. 132/2013, de 5 de junio (Pte. D. Ramón Rodríguez Arribas); STC núm. 166/2014, de 22 de octubre (Pte. D. Ricardo Enriquez Sancho, FJ. 5.); STC núm. 33/2018, de 12 de abril (Pte: D. Ricardo Enríquez Sancho, FJ. 5, b); y STC núm. 55/2018, de 24 de mayo (Pte. D. Andrés Ollero Tassara).

35 STC núm. 130/2013, de 4 de junio (Pte. D. Manuel Aragón Reyes).

${ }^{36}$ STC 166/2014, de 22 de octubre (Pte. D. Ricardo Enriquez Sancho, FF.JJ. $4 .^{\circ}, 5^{\circ}, 6 .^{\circ}$ y $7 .^{\circ}$ ). En esta sentencia se reitera la doctrina sentada en las sentencias 227/1988, de 27 de noviembre, FJ. 32; 98/2001, de 5 de abril, FJ. 8 y 130/2013, de 4 de junio, FJ. 7. Este pronunciamiento ha sido posteriormente reiterado en la STC núm. 143/2017 (Pte. D. ${ }^{a}$ Encarnación Roca Trías). También el Tribunal Supremo viene asumiendo esta doctrina constitucional, sirvan como muestra las sentencias de 26 de enero de 2012 (Pte. D. Ángel Aguallo Avilés); de 2 de octubre de 2014 (Pte. D. Antonio Montero Fernández).

37 La STC núm. 55/2018, de 24 de mayo (Pte. D. Andrés Ollero Tassara) sostiene que: «Se sitúan extramuros del título "procedimiento administrativo común"» (art. 149.1.18 CE) las regulaciones que, aun aplicables a clases enteras de procedimientos, se han adoptado en ejercicio de una competencia estatal más específica. Es el caso, por ejemplo, de los procedimientos de preparación y adjudicación de contratos públicos o de expropiación forzosa; respecto de estos el Estado cuenta con competencias normativas de diverso alcance en materia de contratación administrativa (art. 149.1.18 CE; STC 237/2015, de 19 de noviembre, FJ. 7) y expropiación forzosa (art. 149.1.18 CE; STC 251/2006, de 25 de julio, FJ. 5), respectivamente".

38 STC núm. 55/2018, de 24 de mayo (Pte. D. Andrés Ollero Tassara), en la que se dispone: «No obstante, las bases de una materia "pueden alcanzar algún aspecto de estos procedimientos especiales si imponen criterios directamente vinculados a los objetivos sustantivos" de esa legislación básica, "sin descender a la previsión de trámites de pura gestión; las normas ordinarias de tramitación no pueden considerarse básicas" [STC 54/2017, FJ. 7 b), refiriéndose a la legislación básica, en general; y las SSTC 45/2015, FJ. 6 c), 53/2017, de 17 de mayo, FF.JJ. 3 y 5 b), y 143/2017, FJ. 23, refiriéndose a las "bases medioambientales", en particular]». 
Atendiendo a esta doctrina constitucional, y teniendo en cuenta que el art. 149.1.18 CE atribuye al Estado la competencia exclusiva para regular «la legislación básica sobre contratos...», y que se trata de una materia más específica que la relativa al procedimiento administrativo común, podemos concluir que el procedimiento de contratación administrativa cuenta con una regulación específica y básica del Estado en la Ley 9/2017 CSP; no resultando de aplicación el procedimiento más genérico y abstracto previsto en la Ley 39/2015 PACAP. De lo que se deduce que el significado del principio de transparencia administrativa en la contratación pública hemos de localizarlo, además de en las previsiones ya analizadas de la Ley 19/2013 TBG, en la legislación específica de contratación pública. El principio de transparencia pública, entendido como "publicidad activa» y como "acceso a la información pública» -según su configuración en la Ley 19/2013 TBG- hemos de precisarlo con lo dispuesto en la legislación de contratación pública. En la misma, esa transparencia se concreta en obligaciones para el sector público contratante que van orientadas a la ciudadanía en general, y más concretamente, a los interesados en los procedimientos de contratación.

La relación existente entre la legislación de contratos del sector público y la legislación de procedimiento administrativo común no ha sido una cuestión ajena a la doctrina científica (Martín, 2017:10; Gil, 2018) ni a la jurisprudencia del Tribunal Supremo. Recientemente en la STS de 21 de mayo de 2019, el Alto Tribunal sostiene que en aquellos aspectos de la regulación contractual que carezcan de un procedimiento específico y diferenciado no procede la aplicación supletoria de la legislación de procedimiento administrativo común ${ }^{39}$. A las razones que aporta el Tribunal, orientadas a la existencia de una regulación mínima en la legislación especial de contratación, sería oportuno añadir su doctrina sobre la distribución de competencias en materia procedimental más arriba analizada.

El carácter común especial del procedimiento de contratación pública, que obliga a ceñir las exigencias sobre transparencia pública en la contratación a lo dispuesto en la Ley 9/2017 CSP, no es óbice para que esta se remita en aspectos puntuales de dicho procedimiento a la aplicación de la Ley 39/2015 PACAP ${ }^{40}$. Es más, la declaración de aplicación subsidiaria de la Ley 39/2015 PACAP respecto a los procedimientos regulados en la Ley 9/2017 CSP ${ }^{41}$ obliga a entender que solo es aplicable en defecto de regulación específica en esta ley; no para completar o pormenorizar una regulación más escueta y específica de la propia legislación de contratos.

\subsection{El significado y alcance del principio de transparencia en la contratación del sector público}

\subsubsection{La transparencia en la contratación pública como garantía del Mercado Único}

El principio de transparencia en la contratación pública no aparece referenciado en las Directivas comunitarias de contratación pública de la década de los 70 ni de los $90^{42}$. Su falta de plasmación normativa se va a

39 La STS de 21 de mayo de 2019 (Pte. José Luis Requero lbáñez) resuelve un recurso de casación en el que se plantea si ante la falta de previsión en la LCSP de 2007 de un procedimiento para imponer penalidades en caso de incumplimiento de un contrato resulta o no aplicable lo dispuesto en la legislación de procedimiento administrativo común (más concretamente respecto a la caducidad del procedimiento, o si se trata de un acto administrativo de trámite del procedimiento de ejecución contractual). Al respecto la Sala estima que la imposición de penalidades por incumplimiento contractual no está sujeta a plazo de caducidad, por un lado, porque esas penalidades no responden al ejercicio de la potestad sancionadora, por lo que no se sigue un procedimiento sancionador, ni este se aplica supletoriamente; y por otro lado, dicha penalidad pretende reaccionar ante incumplimientos del contratista y «carece de una vocación sancionadora en sentido estricto, y se configura como una suerte de cláusula penal contractual...cuya razón radica en el interés público que se satisface con el contrato...». Además, añade el Tribunal «[E]n lo procedimental la imposición de penalidades se ubica sistemáticamente en la LCSP...en sede de ejecución contractual, sin que se prevea para su ejercicio un procedimiento específico y diferenciado...». Se concluye por el Tribunal que la regulación mínima que sobre imposición de penalidades contiene la LCSP agota la regulación y «no precisa, por tanto, la aplicación supletoria de la Ley 30/92...». En definitiva, acaba afirmando el Alto Tribunal que en la imposición de penalidades contractuales al amparo del vigente art. 194.2 de la Ley 9/2017 no son aplicables las previsiones sobre caducidad del procedimiento de la legislación de procedimiento administrativo común.

40 Tal es el caso de las causas de nulidad y anulabilidad del contrato -arts. 39 y 40-; revisión de oficio de los actos preparatorios y de adjudicación del contrato y en la suspensión en la ejecución de actos de los órganos de contratación -art. 41-; impugnación de actos de contratación no susceptibles de recurso especial o procedentes de entidades sin consideración de poder adjudicador-arts.44.6 y 321.5-; lugares de presentación del recurso especial y su tramitación -arts.51.3 y 56.-

41 La Disposición Final Cuarta de la Ley 9/2017 dispone, en su apartado primero: «Los procedimientos regulados en esta Ley se regirán, en primer término, por los preceptos contenidos en ella y en sus normas de desarrollo y, subsidiariamente, por los establecidos en la Ley 39/2015...».

42 Así lo demuestra el hecho que de que la Directiva 71/305/CEE, del Consejo, de 26 de julio de 1971 sobre Coordinación de los procedimientos de adjudicación de los contratos públicos de obras, no contuviera ninguna referencia al término; y que la Directiva 77/62/CEE, del Consejo, de 21 de diciembre de 1976, de Coordinación de los procedimientos de adjudicación de los contratos de sumi- 
REALA. Nueva Época - N. 12, octubre-marzo 2019 - ISSN: 1989-8975 - DOI: 10.24965/reala.i12.10714 - [Págs. 6-25]

La transparencia como principio vertebrador de la contratación pública: significado y problemas de articulación normativa

Isabel González Ríos

ir paliando cuando se empieza a ahondar en la implantación del mercado único de la UE, y se ve la necesidad de incidir en la contratación pública; así para Malaret Garcia (Malaret, 2016:32), la UE maneja un concepto más económico que presupuestario de la contratación pública. En esta línea, la primera Directiva comunitaria que generosamente se refiere al citado principio es la Directiva 2004/18/CE, del Parlamento Europeo y del Consejo, de 31 de marzo de 2004, sobre Coordinación de los procedimientos de adjudicación de contratos públicos de obras, de suministros y de servicios ${ }^{43}$; y lo hace como principio derivado -junto a los principios de igualdad de trato, no discriminación, de reconocimiento mutuo y de proporcionalidad- de los principios de libre circulación de mercancías, libertad de establecimiento y libre prestación de servicios que inspiran la UE ${ }^{44}$

Como ha puesto de manifiesto Cerrillo i Martínez (Cerrillo, 2018:121), el TJUE ha venido exigiendo transparencia en la contratación pública como garantía de apertura a la competencia y a la libre concurrencia (SSTJUE de 12 de septiembre de 2000 y de 7 de diciembre de 2000) y como antídoto de la corrupción y de la arbitrariedad (STJUE de 12 de marzo de 2008). Con este sentido se ha plasmado la transparencia en la Directiva 2014/24/CE, sobre contratación pública, que se refiere a ella en su primer considerando como uno de los principios que deben respetar las autoridades competentes en la adjudicación de los $\operatorname{contratos}^{45}$. La UE, consciente de la influencia que tiene la contratación pública en la libre circulación de mercancías, en la libertad de establecimiento y libre prestación de servicios impone que la adjudicación de los contratos se realice de forma transparente con el objeto de que la misma se abra a la competencia. El Preámbulo de esta Directiva se encuentra jalonado de expresas referencias al principio de transparencia en las diferentes fases de la contratación pública ${ }^{46}$, lo que a su vez tiene su correspondiente reflejo en el articulado de la norma ${ }^{47}$. Especial importancia en la determinación del concepto, a falta de una concreta definición en el texto de la Directiva, resulta el Título II, referido a las "[N]ormas aplicables a los contratos públicos”, cuyo Capítulo III dedicado al desarrollo del procedimiento incluye una Sección 2. ${ }^{a}$ titulada "[P]ublicación y transparencia" (arts. 45 a 55). Esta Sección 2. a contiene, por un lado, la regulación de la publicidad (anuncios de información previa a la contratación; de licitación; de adjudicación del contrato; y los criterios de publicación a nivel nacional de los citados anuncios), lo que entendemos forma parte de la llamada publicidad activa; y por otro lado, medidas relacionadas con el acceso a la información sobre el contrato. Entre estas se incluyen: a) la obligación de los poderes adjudicadores de facilitar el acceso libre, directo, completo y gratuito a los pliegos de contratación, a través de medios electrónicos, con los requisitos y límites que establece el art. 53.1; igualmente facilitar información adicional sobre los pliegos de contratación o cualquier documentación complementaria siempre

nistros, se refiriera de forma absolutamente tangencial a la transparencia, al prever que el establecimiento de idénticas condiciones de participación en los contratos de suministros públicos a nivel comunitario garantiza la transparencia y con ella el control del respeto a la libre circulación de mercancías (considerando $2 .^{\circ}$ ). Por su parte, el término transparencia no es utilizado por la Directiva $92 / 50 / C E E$, del Consejo de 18 de junio de 1992, sobre Coordinación de los procedimientos de adjudicación de los contratos públicos de servicios, orientada a la adopción de medidas para la implantación progresiva del mercado interior en el que se garantice la libre circulación de mercancías, personas, servicios y capitales; ni por la Directiva 93/36/CEE del Consejo, de 14 de junio de 1993, sobre Coordinación de los procedimientos de adjudicación de contratos públicos de suministros; ni tampoco por la Directiva 93/37/CEE del Consejo de 14 de junio de 193, sobre coordinación de los procedimientos de adjudicación de los contratos públicos de obras.

43 En términos prácticamente idénticos se pronunciaba la Directiva 2004/17/CE del Parlamento Europeo y del Consejo, de 31 de marzo de 2004, sobre la Coordinación de los procedimientos de adjudicación en los sectores del agua, de la energía, de los transportes y de los servicios postales.

44 Considerando $2^{\circ}$ de la Directiva 2004/18/CE, del Parlamento Europeo y del Consejo, de 31 de marzo de 2004 , sobre Coordinación de los procedimientos de adjudicación de contratos públicos de obras, de suministros y de servicios.

45 Sobre la relevancia de los principios de transparencia, igualdad de trato, objetividad, imparcialidad o equidad en la conformación de un derecho administrativo global en materia de contratación pública, véase: RODRÍGUEZ ARANA, J. (2016): "Los principios del derecho global de la contratación pública", en Revista Española de Derecho Administrativo, REDA, núm. 179, págs. $29-54$.

46 La necesidad de su observancia en los procedimientos de licitación para evitar la «opacidad» y, a la postre, la arbitrariedad, lleva al legislador comunitario a reivindicar la transparencia en los procedimientos de licitación con negociación (considerando 45); en el uso de medios de información y comunicación electrónicos, como métodos de comunicación e intercambio de información; en las comunicaciones orales con los operadores económicos previas a la valoración de las ofertas (considerando 58); en las agregaciones de la demanda que realicen los compradores públicos para obtener ventajas de las economías de escala (considerando 59); en los acuerdos marco de contratación (considerando 61); en la compra electrónica (considerando 68); en las normas de contratación conjunta transfronteriza (considerando 73); en la tramitación de los procedimientos, respecto de las decisiones que vaya adoptando el poder adjudicador, respecto de los interesados (considerando 82); en la adjudicación del contrato (considerando 90); en la subcontratación pública (considerando 105); en las resoluciones del contrato por deficiencias en su ejecución (considerando 110); en los contratos de servicios a personas (considerando 114); en el acceso a los documentos de las personas interesadas en el procedimiento (considerando 126).

47 Al término transparencia se refiere la Directiva 2014/24/UE como principio de actuación de los poderes adjudicadores (art. 18); como límite a las consultas preliminares del mercado antes de iniciar el procedimiento de contratación (art. 40); como exigencia en los procedimientos en los que se otorgue una etiqueta que acredite características de tipo medioambiental, social u otro en obras, suministros o servicios (art. 43.1.c); como principio a tener en cuenta en la selección y adjudicación del contrato (arts. 56 y 76). 
que se solicite previamente a la fecha límite de recepción de las ofertas (art. 53.2); b) la invitación a los candidatos en aquellos procedimientos que no sean abiertos (restringidos, de diálogo competitivo, asociaciones para la innovación, de licitación con negociación), con indicación de la dirección electrónica donde pueden consultarse los pliegos de contratación (art. 54); c) la comunicación a los candidatos y licitadores de las decisiones tomadas en torno a la celebración de un acuerdo marco, a la adjudicación del contrato, a la admisión a un sistema dinámico de adquisición (art. 55.1).

En la misma línea, la Directiva 2014/23/CE, relativa a la adjudicación de Contratos de concesión también contiene importantes alusiones a la transparencia en este tipo de contratos. Especialmente relevante resulta el art. 3 por cuanto consagra el principio de igualdad de trato, no discriminación y transparencia, en el que se vuelve a incidir en la necesidad de que los poderes adjudicadores den un trato igualitario y no discriminatorio a los operadores económicos y actúen de «forma transparente y proporcionada»; a su vez, fija como objetivo de los poderes adjudicadores «garantizar la transparencia del procedimiento de adjudicación y de la ejecución del contrato» respetando al mismo tiempo los deberes de confidencialidad ${ }^{48}$. Dicha actuación transparente en el procedimiento de adjudicación de las concesiones se hace efectiva a través del anuncio de la concesión (art. 31); del anuncio de la adjudicación (art. 32); del acceso electrónico a los documentos relativos a las concesiones (art. 34); de la exigencia a los poderes adjudicadores para que tomen medidas contra el fraude, el favoritismo y para luchar contra los conflictos de interés (art. 35); imponiendo garantías procedimentales de transparencia en la determinación de: a) las especificaciones técnicas y funcionales de las obras y servicios objeto de concesión, con el objeto de no restringir la competencia (art. 36); y b) los criterios de adjudicación de la concesión (art. 37 y 41$)^{49}$.

En definitiva, la Unión Europea relaciona la transparencia en la contratación pública con la libertad de circulación (de mercancías, servicios, capitales y personas); y tiene como objetivo garantizar la libre competencia y concurrencia en dicho sector, como mecanismo para el establecimiento del Mercado Único. Dicha transparencia se hace efectiva mediante medidas como la publicidad de las actuaciones contractuales y la garantía del acceso electrónico al procedimiento de contratación.

\subsubsection{La transparencia como principio vertebrador de la contratación pública en la Ley 9/2017 CSP}

La transposición al Derecho interno de las Directivas 2014/23/CE y 2014/24/CE a través de la Ley 9/2017 CSP nos permite profundizar en las obligaciones de transparencia pública que se exigen en el Derecho interno español, que -como ha sostenido Gimeno Feliu (Feliu, 2017:48)- ha venido adoleciendo de un déficit de transparencia. Sin perjuicio de las obligaciones de publicidad activa relativa a los contratos y del genérico derecho de acceso a la información pública que regula la Ley 19/2013 TBG -como elementos configuradores de la transparencia pública-, la concreción de qué deba entenderse por la citada transparencia en la contratación pública hemos de buscarla en la Ley 9/2017 CSP (Gimeno, 2018:34). Del Preámbulo y del art. 1 de dicha disposición se deduce que la transparencia en la contratación pública se erige en uno de los objetivos y fines ${ }^{50}$ que pretende alcanzar el legislador de 2017 y, en consecuencia se concibe como un logro a conseguir con el tiempo; constituye uno de los motivos por los que aprueba la Ley; y de forma más concreta es un principio básico de actuación en la contratación. Así, para que esa transparencia en la contratación pública sea efectiva se arbitran mecanismos como la publicación electrónica del Perfil del Contratante; el fomento de la contratación electrónica; y la inscripción registral de los contratos -como instrumento al servicio de la publicidad y de la transparencia (Ortega, 2006:93)-; elementos que podemos considerar transversales a todo procedimiento

48 El art. 28 de la Directiva 2014/23/CE, del Parlamento Europeo y del Consejo, de 26 de febrero de 2014, relativa a la adjudicación de los contratos de concesión, se refiere a esos deberes de confidencialidad respecto a la información facilitada por los operadores económicos que estos designen como confidencial, a salvo de las obligaciones relativas a la publicidad de los contratos de concesión adjudicados y de la información que debe facilitarse a candidatos y licitadores.

49 Completando el marco normativo de la UE en materia de transparencia en la contratación pública, la Directiva 2014/25/CE relativa a la Contratación por entidades que operan en los sectores del agua, la energía, los transportes y los servicios postales, de forma homóloga a la Directiva 2014/23/CE, contiene continuas referencias a la transparencia en este tipo de contratos. Su Título II, relativo a las normas aplicables a los contratos, en su Capítulo III dedicada al desarrollo del procedimiento de contratación incluye la Sección 2 a $^{\text {a }}$ sobre "Publicación y transparencia" (arts. 67-75) con similar contenido al previsto en la Directiva 2014/23/CE.

50 Entre la variedad de fines que recoge el art. 1 de la Ley 9/2017 CSP (garantizar principios como la libertad de acceso a las licitaciones, la no discriminación e igualdad de trato a los licitadores, el principio de integridad; la estabilidad presupuestaria y control del gasto; la salvaguarda de la libre competencia; selección de la oferta más ventajosa; incorporación de criterios sociales y medioambientales; acceso a la contratación de pymes...) se incluye el «principio de publicidad y transparencia de los procedimientos». 
de contratación pública y que de hecho se reiteran a lo largo del articulado de la Ley 9/2017 CSP. Junto a ellos se prevén concretas exigencias de transparencia pública insertas en el procedimiento de contratación.

Por lo que respecta al primer aspecto, de especial interés resulta la regulación de la figura del Perfil del Contratante, que como señala el Preámbulo de la Ley cumple «un papel principal como instrumento de publicidad de los distintos actos y fases de la tramitación de los contratos de cada entidad». Como indica el art. 63.1 Ley 9/2017 CSP, la publicidad a través de internet del perfil del contratante (que agrupa información y documentos sobre su actividad contractual) tiene por objeto asegurar la «transparencia y el acceso público a los mismos». Este acceso será libre y estará accesible durante un periodo no inferior a 5 años. Este ejemplo de publicidad activa en materia de contratación pública se refuerza con la posibilidad de acceder a expedientes anteriores a los últimos 5 años mediante solicitud de información. El principio de transparencia se hace efectivo a través de la difusión de «cualesquiera datos y documentos» de la actividad contractual, y en todo caso, la información general para relacionarse con el órgano de contratación (puntos de contacto, números de teléfono y fax, dirección postal, dirección electrónica), informaciones, anuncios y documentos generales, y la información particular sobre los contratos que celebre ${ }^{51}$; la decisión de no adjudicar o celebrar el contrato; la interposición de recursos...Del conjunto de información y documentos que deben publicarse en el Perfil del Contratante merece especial atención la necesidad de indicar el cargo de los miembros de las Mesas de contratación y Comités de expertos, sin que sirvan alusiones genéricas o indeterminadas; como técnica que contribuye a la visibilidad de la actuación pública y a evitar la corrupción. A mayor transparencia menor posibilidad de incurrir en corrupción.

Respecto al fomento de la contratación electrónica, la cual viene a garantizar la difusión del Perfil del contratante, elemento clave en la transparencia en la contratación pública, se crea la Plataforma de Contratación del Sector Público -PCSP- (art. 347) ${ }^{52}$ que, dependiente de la Dirección General del Patrimonio del Ministerio de Hacienda y Función Pública, debe ponerse a disposición de todos los órganos de contratación del sector público. Las Comunidades autónomas y las Ciudades Autónomas de Ceuta y Melilla pueden establecer servicios de información similares, lo que no les exime de publicar en la PCSP la convocatoria de todas las licitaciones y comunicaciones ${ }^{53}$.

A la transparencia en la contratación pública también contribuye la regulación en los arts. 346 y siguientes de la Ley 9/2017 CSP del Registro de Contratos del Sector Público, que se concibe como «sitio oficial central de información sobre la contratación pública en España», en el que se registran todos los contratos adjudicados, debiendo comunicarse para ello los datos relativos a los contratos por importe igual o superior a 5.000 euros. Depende del Ministerio de Hacienda y Función Pública (actual Ministerio de Hacienda). Además de garantizar la publicidad activa de los contratos, sirve a la publicidad pasiva o derecho de acceso público a los datos que no tengan carácter de confidenciales y que no hayan sido previamente publicados de modo electrónico y a través de internet.

Veamos de forma pormenorizada cómo se plasma normativamente la exigencia de transparencia en la contratación pública. Las concretas exigencias que impone la Ley 9/2017 CSP sirven para reducir la discrecionalidad, dificultan la desviación de poder y, a la postre, la arbitrariedad y la corrupción en la contratación pública, como ha apreciado un destacado sector doctrinal (Mellado, 2017:209; Gimeno, 2017:47,Cerrillo, 2014 $)^{54}$. Así, la regulación más detallada y exigente en esta materia se centra en los contratos que celebran las Administraciones públicas ${ }^{55}$ regulados en el Libro Segundo, Título I, y se plasma durante toda la vida del contrato, desde la preparación y adjudicación hasta la fase de ejecución y

51 En cuanto a la información particular relativa a los contratos que celebre debe publicarse: la memoria justificativa del contrato, la justificación del procedimiento utilizado para su adjudicación si no se utiliza el procedimiento abierto o el restringido, el pliego de cláusulas administrativas particulares y el de prescripciones técnicas; el documento de aprobación del expediente; el objeto detallado del contrato, su duración y presupuesto de licitación; los anuncios de información previa, la convocatoria de licitaciones, de adjudicación, etc (art. 63.3).

52 A la Plataforma de Contratación del Sector Público y a las Plataformas de contratación que utilizan algunas Comunidades Autónomas se encuentran disponibles en: https://contrataciondelestado.es/wps/portal/plataforma.

53 Sobre la práctica de notificaciones y comunicaciones por medios electrónicos, vid., la Disposición Adicional Decimoquinta y Disposición Adicional Decimosexta.

CERRILLO I MARTÍNEZ, A. (2018), "Datos masivos y datos abiertos para una gobernanza inteligente", en El Profesional de la Información, núm. 5, págs. 1.118-1.135, anuda el avance de la gobernanza inteligente a la disposición de datos de calidad y a su fácil utilización.

54 Véase nota núm. 2.

55 El principio de transparencia también debe presidir la aprobación de instrucciones en las que, las entidades del sector público que no tengan carácter de poderes adjudicadores, regulen los procedimientos de contratación. Dichas instrucciones además de ponerse a disposición de todos los interesados en los procedimientos de adjudicación de los contratos que regulen, han de publicarse en el Perfil del Contratante de la entidad (art. 321 LCSP). 
extinción (Moreno, 2016:26). En la preparación del contrato, las consultas preliminares a los operadores económicos deben realizarse sin falsear la competencia o vulnerar los principios de no discriminación y de transparencia (art. 115.2). Como garantía de esa transparencia, el órgano de contratación debe hacer constar las consultas y demás actuaciones realizadas en un informe, que formará parte del expediente de contratación y al que debe darse publicidad en el Perfil del Contratante del órgano de contratación (art. 115.3). Tampoco es ajena la exigencia de transparencia administrativa por lo que respecta al expediente de contratación. La resolución motivada por el órgano de contratación, por la que se aprueba el citado expediente, y que conlleva la apertura del procedimiento de adjudicación, debe ser objeto de publicación en el Perfil del Contratante (art. 117.1) ${ }^{56}$.

Siguiendo con el procedimiento de contratación, la transparencia como principio informador de la contratación pública (Razquin, 2018:195; Moreno, 2017:2799) debe regir en la adjudicación del contrato, en la relación entre los órganos de contratación y los licitadores y candidatos (art. 132.1) ${ }^{57}$. Pero la transparencia en la adjudicación también conlleva obligaciones relacionadas con la publicidad. En primer lugar, la publicación del anuncio de información previa (de carácter potestativo, para dar a conocer los contratos sujetos a regulación armonizada que tengan proyectado adjudicar -art. 134-) y del anuncio de licitación para la adjudicación de contratos de las Administraciones públicas en el Perfil del Contratante (art. 135) ${ }^{58}$. En segundo lugar, la publicación en el Perfil del Contratante, por un lado, de la resolución de adjudicación (que debe contener los candidatos descartados y los excluidos y su justificación; el nombre de los adjudicatarios y características y ventajas de su proposición) -art. 151-, publicación que debe acompañarse con la comunicación a candidatos y licitadores de las decisiones tomadas en orden a la adjudicación del contrato -art. 155.1-; y por otro lado, de la formalización del contrato, aunque excepcionalmente se permite no publicar determinados datos de celebración del contrato ${ }^{59}$. La amplitud y laxitud, en algunos casos, de los supuestos en los que el órgano de contratación puede decidir la no publicación de datos contractuales (cuando se pueda obstaculizar la aplicación de una norma; resulte contrario al interés público; perjudique intereses comerciales legítimos o la competencia; en contratos declarados secretos o reservados o cuya ejecución deba ir acompañada de medidas de seguridad especiales, etc) muestra la «debilidad» de la transparencia en la contratación pública y el conflicto siempre latente entre la transparencia y la confidencialidad de datos contractuales, a los que se ha referido Razquin Lizarraga y Medina Guerrero (Razquin, 2018:1.615; Medina, 2018:33) $)^{60}$.

Como manifestación del derecho de acceso a la información pública, el art. 138 LCSP recoge el acceso libre, directo, completo y gratuito a los pliegos y demás documentación complementaria, a través del Perfil del Contratante, desde la fecha de publicación del anuncio de licitación o desde el envío de la invitación a los candidatos seleccionados. Excepcionalmente, el acceso podrá no ser electrónico (cuando circunstancias técnicas lo impidan; por razones de confidencialidad, por motivos excepcionales de seguridad en concesiones de obras y servicios). Además, los candidatos y licitadores descartados tienen derecho a acceder a la información relativa a los motivos de la decisión, y los licitadores que hayan presentado una oferta admisible a conocer las ventajas y características de la oferta seleccionada (art. 155. 2 LCSP) ${ }^{61}$.

56 Tratándose de contratos menores el expediente de contratación debe realizarse al menos trimestralmente, debiendo publicarse en el Perfil del Contratante al menos su objeto, duración, importe de adjudicación, el adjudicatario; se exceptúan de esta publicidad los contratos por valor estimado inferior a 5.000 euros, siempre que el sistema de pago fuera el anticipo de caja u otro sistema similar (arts. 63.4 y 118.4 LCSP). Esta última excepción abre la puerta a la quiebra de la transparencia en los contratos públicos.

57 De forma más concreta, el principio de transparencia debe tenerse en cuenta al establecer los criterios de adjudicación del contrato, que figuran en el pliego de cláusulas administrativas particulares y en el anuncio de licitación. Sin embargo, no se aclara qué elementos o características configuran dicho principio, si bien el hecho de que el legislador establezca que los criterios de adjudicación «no conferirán al órgano de contratación una libertad de decisión ilimitada» (art. 145.5 LCSP), parece indicar que el principio de transparencia se orienta a limitar la discrecionalidad en el establecimiento de los criterios de adjudicación.

58 Publicados también en el BOE cuando se trate de contratos celebrados por la Administración General del Estado o entidades vinculadas, y en el Diario Oficial de la Unión Europea (DOUE) cuando sean contratos sujetos a regulación armonizada.

$59 \mathrm{El}$ art. 154 LCSP permite en supuestos tasados previstos en su apartado $7 .^{\circ}$, no publicar determinados datos de celebración del contrato exigiéndose un previo informe del Consejo de Transparencia y Buen Gobierno sobre si prevalece el derecho de acceso a la información pública o no sobre los bienes que se tratan de salvaguardar con la no publicación.

60 El Informe 11/2013, de 26 de julio, de la Junta Consultiva de Contratación de la Generalitat de Cataluña dispone que la confidencialidad en la contratación pública debe compatibilizarse con las exigencias de transparencia, mediante la realización de una ponderación de los bienes jurídicos a proteger.

61 También la comunicación a los licitadores o candidatos de datos relativos a la celebración del contrato puede no llevarse a cabo por varias razones (cuando la divulgación pueda obstaculizar la aplicación de la ley, ser contraria al interés público, perjudicar los intereses comerciales legítimos o la competencia leal entre empresarios) -art. 155.3 Ley 9/2017 CSP-. 
También en la regulación de los procedimientos de adjudicación del contrato ${ }^{62}$ (procedimiento abierto, procedimiento abierto simplificado, procedimiento restringido, procedimientos con negociación, procedimiento negociado sin publicidad...) podemos resaltar como aspecto relacionado con la transparencia pública la posibilidad de los licitadores que hayan presentado una oferta admisible de solicitar por escrito que se les comunique el desarrollo de las negociaciones, debiendo facilitarse esa información, sin perjuicio de no comunicar datos que se consideren confidenciales (art. 171, que reitera lo dispuesto en el art. 155.1.d).

Más escuetas resultan las referencias a la transparencia pública en lo relativo a la ejecución y extinción del contrato. Al margen de la publicación en el Perfil del Contratante de aspectos relevantes relacionados con estas fases contractuales como las modificaciones de que sea objeto el contrato, la interposición de recursos y la suspensión con motivo de los mismos (art. 63); o que en el Registro de Contratos del Sector Público se hagan constar «...las modificaciones, prórrogas, variaciones de plazos o de precio, importe final y extinción de aquellos» (art. 346.3).

\section{EL CONTROL DE LA FALTA DE TRANSPARENCIA EN LA CONTRATACIÓN PÚBLICA}

La transparencia en la contratación pública es una exigencia que se predica del sector público, y especialmente de las Administraciones públicas, en los términos dispuestos en la Ley 9/2017 de CSP. En consecuencia, los incumplimientos en esta materia pueden dar lugar: a) a la presentación del recurso especial en materia de contratación, cuando el incumplimiento de actuaciones de transparencia se refiera a los contratos y actos recogidos en el art. 44; b) a la interposición del recurso de alzada o potestativo de reposición cuando afecten a actos de preparación, adjudicación, ejecución o extinción del contrato que no sean susceptibles del recurso especial (art. 44.6). Tanto en los supuestos referidos en el apartado a) como en el b), las resoluciones administrativas de esos recursos son impugnables ante la Jurisdicción Contencioso-administrativa. A tal efecto, hay que tener en cuenta que el art. 38 de la Ley 9/2017 CSP considera un vicio de invalidez de los contratos celebrados por los poderes adjudicadores «cuando lo sea alguno de sus actos preparatorios o del procedimiento de adjudicación, por concurrir en los mismos alguna de las causas de Derecho Administrativo». Y entre las causas de nulidad de pleno derecho específicas de la contratación pública, por lo que ahora nos interesa, procede referirse a «la falta de publicación del anuncio de licitación en el Perfil del Contratante», en el "Diario Oficial de la Unión Europea" o en el medio de publicidad en que sea preceptivo, de conformidad con el art. 135, según dispone el art. $39 \mathrm{c})^{63}$. A su vez, como causas de anulabilidad que pueden derivarse de incumplimientos en materia de transparencia pública en la contratación se encuentran las «disposiciones, resoluciones, cláusulas o actos emanados de cualquier poder adjudicador que otorguen, de forma directa o indirecta ventajas a las empresas que hayan contratado previamente con cualquier Administración» (art. 40 b).

Al mismo tiempo, y sin perjuicio de los efectos y medidas que se deducen de la Ley 9/2017 CSP, ante actuaciones contractuales "carentes de la debida transparencia» procede también la aplicación de los mecanismos que arbitra la Ley 19/2013 TBG con ciertas puntualizaciones. Así, pues, de conformidad con el art. 9 de esta ley corresponde al Consejo de Transparencia y Buen Gobierno controlar el cumplimiento por la Administración General del Estado de las obligaciones de publicidad activa (entre las que recordemos se sitúa las relativas a los contratos) ${ }^{64}$. Para ello podrá dictar resoluciones en las que se establezcan las medidas que sea necesario adoptar para el cese del incumplimiento y el inicio de las actuaciones disciplinarias que procedan (art. 9.2); constituyendo infracción grave «el incumplimiento reiterado» de las obligaciones de publicidad activa, procediendo la aplicación a los responsables del régimen disciplinario previsto en la correspondiente normativa reguladora (art. 9.3). Por tanto, actuación del Consejo de Transparencia y Buen Gobierno - u órgano equivalente autonómico- para que cesen los incumplimientos relativos a la falta de transparencia en la contratación pública y posible inicio del procedimiento disciplinario ${ }^{65}$. Ahora bien, cuando

62 Arts. 156 y siguientes de la Ley 9/2017 CSP.

63 La nulidad por incumplimiento de publicidad, y su afectación a la transparencia, ha sido reivindicada por GIMENO FELIÚ, J. M. ${ }^{a}$ (2017): "Medidas de prevención de corrupción y refuerzo de la transparencia en la contratación pública", op. cit., pág. 59.

64 Competencias que ostentan los órganos homólogos de las Comunidades Autónomas respecto a actuaciones de la Administración autonómica y local ( $v$. gr. El consejo de Transparencia y Protección de Datos de Andalucía que controla el cumplimiento de la publicidad activa según el art. 23 de la Ley 1/2014, de 24 de junio de Transparencia Pública de Andalucía).

65 La aplicación del régimen disciplinario, el cual tiene como destinarios a los funcionarios públicos y al personal laboral al servicio de las Administraciones públicas, conlleva una rémora en la contratación pública transparente, que deriva del hecho de que constituya una infracción muy grave «la publicación o utilización indebida de la documentación o información a que tengan o haya tenido acceso por 
aquella no publicación vaya referida al acto de formalización del contrato, respecto a algunos de sus datos, las funciones del Consejo de Transparencia y Buen Gobierno se limitan a la emisión de un informe ${ }^{66}$.

Cuando las infracciones en materia de transparencia se refieran a la denegación del derecho de acceso a la información pública en materia contractual ${ }^{67}$, reconocido en el articulado de la Ley 9/2017 CSP, ¿puede el interesado al que se le deniegue el acceso, de forma expresa o presunta, presentar reclamación ante el Consejo de Transparencia y Buen Gobierno en los términos dispuestos en el art. 23 y siguientes de la Ley 19/2013 TBG? En el caso de impugnación de actuaciones que afecten al derecho de acceso a la información contractual por parte de un interesado en un procedimiento que se esté tramitando no resulta admisible la doble vía, la prevista en la Ley 19/2013 TBG y la que recoge la Ley 9/2017 CSP, o sea, la utilización de la reclamación potestativa ante el Consejo de Transparencia y Buen Gobierno -u órgano autonómico- y el sistema de recursos que arbitra la Ley 9/2017 CSP. Así lo dispone la propia Ley 19/2013 TBG, en cuya Disposición Adicional Primera remite a la específica legislación de procedimiento (en este caso la Ley 9/2017 de CSP). En caso contrario, la solución a un mismo problema relacionado con la transparencia pública (acceso a la información contractual) podría tener distintas resoluciones según que los interesados acudieran al Consejo de Transparencia o al órgano competente en materia contractual, lo que dificultaría la unidad de criterio. Ello no impide que quienes no ostenten la condición de interesados en el procedimiento, y en el caso de procedimientos ya finalizados, tanto los anteriores interesados como cualquier persona, puedan utilizar las vías de impugnación a que se refiere la legislación de transparencia. Aunque también es cierto que esta posibilidad resultará más limitada dada la amplia obligación de publicidad activa que se predica de toda actividad contractual, lo que garantiza el acceso público.

\section{CONSIDERACIONES FINALES}

1. La transparencia pública es una exigencia que el TFUE anuda a la buena gobernanza y a la participación ciudadana, en un reconocimiento abstracto y general respecto a toda la actuación pública. Podemos decir que la transparencia tiene dos caras, una interna, que afecta a la actuación de las Administración públicas y otras entidades públicas y privadas (que ha de ser transparente, visible), y otra, externa, que se predica de la relación con la ciudadanía, y que se manifiesta en el derecho a conocer la actuación pública y a participar en los asuntos públicos.

Pero ese reconocimiento genérico que se realiza a nivel comunitario se concreta en materia de contratación pública, quedando la transparencia circunscrita al fortalecimiento del mercado interior, de tal manera que la contratación pública transparente va a garantizar la libre circulación (de mercancías, personas, servicios...). A sensu contrario, una contratación pública falta de transparencia dificulta o impide el desarrollo del mercado interior europeo y consecuentemente vulnera el TFUE.

2. Con apoyo en lo dispuesto en el TFUE y en nuestra CE que consagra el principio de eficacia -en el que se integraría la transparencia- en la actuación administrativa, nuestro Ordenamiento jurídico viene desarrollando todo un marco normativo con el que poder garantizar la transparencia pública; como hito más relevante la Ley 19/2013 TBG y sus similares leyes autonómicas. Marco normativo general que hay que complementar con el previsto en aquellos sectores íntimamente relacionados con el gasto público, como la contratación pública. Así, en la Ley 9/2017 CSP encontramos las manifestaciones, los mecanismos específicos y los concretos objetivos de la transparencia pública en este ámbito material.

3. De la Ley 19/2013 de TBG tenemos que resaltar que haya hecho extensiva la exigencia de transparencia pública no solo a entes del sector público (Administraciones públicas y otras entidades públicas y

\footnotetext{
razón de su cargo o función», «la negligencia en la custodia de secretos oficiales, declarados así por ley o clasificados como tales, que sea causa de su publicación o que provoque su difusión o conocimiento indebido» (art. 29.1, d) y e) de la Ley 19/2013 TBG; en los mismos términos se pronuncia el art. 95.2. e) y f) del Real Decreto Legislativo 5/2015, de 30 de octubre, por el que se aprueba el Texto Refundido del Estatuto Básico del Empleado Público); y como infracción grave «no guardar el debido sigilo respecto a los asuntos que se conozcan por razón del cargo, cuando causen perjuicio a la Administración o se utilice en provecho propio» (art. 29.2.d) Ley 19/2013 TBG).

66 El art. 154.7 Ley 9/2017 CSP dispone que la formalización del contrato debe ser objeto de publicación; pero podrán no publicarse datos relativos a la celebración del contrato para garantizar aspectos de confidencialidad. En tales supuestos se debe pedir un informe al Consejo de Transparencia y Buen Gobierno sobre si prevalece el derecho de acceso a la información pública o los bienes que se tratan de salvaguardar con la no publicidad de datos.

67 Tengamos en cuenta que, sin ceñirse exclusivamente al ámbito de la contratación pública, el art. 20.6 de la Ley 19/2013 TBG dispone que el incumplimiento reiterado de la obligación de resolver en plazo las solicitudes de acceso se considera infracción grave a efectos de aplicar el correspondiente régimen disciplinario.
} 
privadas), sino también, a órganos constitucionales y autonómicos y a entes privados. ¿Y el Gobierno y altos cargos? ¿Están sujetos a obligaciones de transparencia? Las exigencias de buen gobierno que establece la Ley 19/2013 TBG recoge el principio de transparencia en la gestión de los asuntos públicos, a lo que se suma la legislación específica sobre altos cargos.

A esa expansión subjetiva de la transparencia se une su extensión objetiva o material, como ocurre en el ámbito de la contratación pública, donde la Ley 19/2013 TBG impone unas exigencias de transparencia, que podemos calificar de «mínimas», que se han visto superadas y pormenorizadas por la Ley 9/2017 de CSP, por exigencia del derecho de la Unión Europea.

4. Por lo que respecta a la relación entre la Ley 39/2015 PACAP y la Ley 9/2017 CSP, de la distribución constitucional de competencias en materia de procedimiento administrativo común y en contratación pública y de la doctrina sentada por el Tribunal Constitucional se deduce que la regulación del procedimiento administrativo de contratación pública obedece a una competencia estatal básica y específica que determina la aplicación de la Ley 9/2017 de CSP en detrimento de la Ley 39/2015 PAC. Ello a salvo de las remisiones que en materia de contratación se realizan a dicha legislación procedimental común. En consecuencia, los aspectos relacionados con la transparencia pública en la contratación tienen su sede habitual en la legislación de contratación del sector público, sin que el principio de subsidiariedad que plasma la Disposición Final Cuarta de la Ley 9/2017 CSP respecto a la legislación de procedimiento administrativo común pueda ser entendido a modo de supletoriedad -lo que chocaría con el propio carácter de procedimiento común especial que tiene el procedimiento de contratación-, sino en el sentido de que podrá acudirse a las previsiones de la Ley 39/2015 PAC cuando el procedimiento de contratación «no pueda por sí solo alcanzar los objetivos de transparencia que derivan del derecho de la Unión Europea y del derecho interno».

5. ¿Pero qué debe entenderse por transparencia en la contratación pública? A falta de su definición en las Directivas de Contratación Pública, hemos de deducir su concepto de su configuración en las mismas y en el Derecho interno. Las Directivas comunitarias vinculan la transparencia con la visibilidad, la apertura al conocimiento público de la celebración del contrato y con la participación de candidatos y licitadores a través del uso de medios electrónicos. En el Derecho interno, la Ley 9/2017 CSP configura la transparencia con carácter subjetivo y abstracto al consagrarse como principio de actuación de los órganos contratantes. Subjetividad que se objetiviza con la previsión de concretas obligaciones de publicidad activa y de respeto al derecho de acceso a la información contractual; principalmente a través de medios electrónicos. Se reduce así el margen de discrecionalidad administrativa en la contratación pública, y con ella el riesgo de arbitrariedad y corrupción.

No obstante, las excepciones a la publicidad de los contratos menores y las exigencias de respeto a la confidencialidad, unido a las responsabilidades disciplinarias en las que puede incurrir el personal al servicio de las Administraciones públicas por uso indebido de la información pública, pueden relativizar las exigencias de transparencia. Pero el amplio reconocimiento legal de exigencias concretas en materia de transparencia abre el camino a la consolidación de una buena administración en esta materia y con ella una limitación o freno para las actuaciones de corrupción en altos cargos y en el Gobierno.

6. En materia de recursos contra actuaciones que falten al deber de transparencia en la contratación pública sería conveniente que el legislador en la Ley 9/2017 CSP clarificara cómo se articula la aplicación del régimen de impugnaciones previsto en la misma con el sistema de control que prevé la Ley 19/2013 de TBG. Al respecto, si bien no vemos inconveniente en la aplicación simultánea de ambas normas respecto a reclamaciones en materia de publicidad activa; aquel doble régimen de control no resulta admisible en el caso de denegación del derecho de acceso a la información pública a interesados en un procedimiento contractual en curso, por el riesgo de posibles resoluciones administrativas contradictorias en materia de transparencia en la contratación pública. Tampoco se admitiría la doble vía de impugnación, limitándose exclusivamente a la prevista en la legislación de transparencia pública, cuando la denegación del acceso venga referida a una solicitud realizada por un no interesado en el procedimiento o respecto de procedimientos contractuales ya concluidos.

\section{BIBLIOGRAFÍA}

AGUDO GONZÁLEZ, J. (2013): "Sobre la europeización del derecho y la evolución de la teoría del procedimiento administrativo", en Revista Española de Derecho Europeo, núm. 45, págs. 61-111.

BARNÉS VÁZQUEZ, J. (coord.) (1993): El procedimiento administrativo en el derecho comparado. Madrid: Civitas.

BARRERO RODRÍGUEZ, C. (2016): "Transparencia de la actividad pública. En particular, el derecho de acceso a la información", en TRIA. Revista Archivística de la Asociación de Archiveros de Andalucía, núm. 20, págs. 239-253. URL: https://www.archiverosdeandalucia.org/wp-content/uploads/2019/04/concepcion-barrero-tria-20-10.pdf. 
REALA. Nueva Época - N. 12, octubre-marzo 2019 - ISSN: 1989-8975 - DOI: 10.24965/reala.i12.10714 - [Págs. 6-25]

La transparencia como principio vertebrador de la contratación pública: significado y problemas de articulación normativa

Isabel González Ríos

BARRERO RODRÍGUEZ, C. (2014): "Transparencia: ámbito subjetivo", en GUICHOT REINA, E. (coord.): Transparencia, acceso a la información pública y buen gobierno: estudio de la Ley 19/2013, de 9 de diciembre, págs. 63-96. Madrid: Tecnos.

CARRILLO, M. (2015): "Transparencia y derechos de acceso a la información en las Administraciones Públicas”, en Parlamento y Constitución: anuario, núm. 17, págs. 267-284.

CASADO CASADO, L. (2014): "Estudio sobre el alcance de la supletoriedad de la Ley 19/2013, de 9 de diciembre, de Transparencia, acceso a la información pública y buen gobierno sobre la Ley 27/2006, de 18 de julio, Reguladora del derecho de acceso a la información ambiental", en Revista Vasca de Administración Pública. HerriArduralaritzako Euskal Aldizkaria, RVAP, núm. 99-100, págs. 819-846.

CERRILLO I MARTÍNEZ, A. (2018): "Contratación electrónica y transparencia: fundamentos necesarios de la contratación abierta", en Cuadernos de Derecho Local, QDL, núm. 48, págs. 121-149.

CERRILLO I MARTÍNEZ, A. (2017): Contractació oberta. [Barcelona]: Generalitat de Catalunya. 1. a ed. Colección Govern obert, 4. Disponible en: http://governobert.gencat.cat/es/que-es/Publicacions/colleccio-govern-obert/4_ contractacio-oberta-agusti-cerrillo-i-martinez/.

CERRILLO I MARTÍNEZ, A. (2014): El principio de integridad en la contratación pública: mecanismos para la prevención de los conflictos de intereses y la lucha contra la corrupción. Navarra: Thomson Reuter Aranzadi.

CERRILLO I MARTÍNEZ, A. (2016): "Las compras abiertas y la prevención de la corrupción”, en Gestión y Análisis de Políticas Públicas, GAPP, núm. 15. DOI: https://doi.org/10.24965/gapp.v0i15.10314.

CERRILLO I MARTÍNEZ, A. (2018), "Datos masivos y datos abiertos para una gobernanza inteligente", en El Profesional de la Información, núm. 5, págs. 1.118-1.135.

COTINO HUESO, L. (2017): "La regulación del uso de medios electrónicos en la difusión activa de información pública y el ejercicio del derecho de acceso", en MARTIN DELGADO, I. (dir.): La reforma de la administración electrónica: una oportunidad para la innovación desde el Derecho, págs. 397-432. Madrid: Instituto Nacional de Administración Pública, INAP.

DÍEZ SÁNCHEZ, J. J. (2017): "Consideraciones críticas a propósito de los planteamientos generales de las Leyes 39 y 40 de 2015 y el procedimiento seguido para su elaboración”, en LAGUNA DE PAZ, J. C., SANZ RUBIALES, I. y DE LOS MOZOS TOUYA, I. (coords.): Derecho Administrativo e integración europea: estudios en homenaje al profesor José Luis Martínez López-Muñiz: Tomo I. El ser de la Administración Pública, págs. 471-490. Madrid: Reus.

FERNÁNDEZ ACEVEDO, R. y VALCARCEL FERNÁNDEZ, P. (dirs.) (2014): La contratación pública a debate: presente y futuro. Navarra: Civitas.

FERNÁNDEZ RAMOS, S. (2018): “La transparencia pública: pasado, presente y futuro”, en Revista Aragonesa de Administración Pública, RArAP, núm. 51, págs. 213-243. URL: http://bibliotecavirtual.aragon.es/bva/i18n/catalogo_ imagenes/grupo.cmd?path $=3717846$.

FERNÁNDEZ RAMOS, S. (2017): "La reclamación ante los órganos de garantía del derecho de acceso a la información pública", en Revista General de Derecho Administrativo, RGDA, núm. 45.

FERNÁNDEZ RAMOS, S. (2013): "El acceso a la información en el Proyecto de Ley de transparencia, acceso a la información pública y buen gobierno”, en Revista Aragonesa de Administración Pública, RArAP, núm. 14, págs. 233-298. URL: http://bibliotecavirtual.aragon.es/bva/i18n/catalogo_imagenes/grupo.cmd?path=3712809.

FERNÁNDEZ RAMOS, S., y PÉREZ MONGUIÓ, J. M. a (2017): El Derecho al Acceso a la Información Pública en España. Navarra: Thomson Reuters Aranzadi.

FUERTES LÓPEZ, M. (coord.) (2012): Un procedimiento administrativo para Europa. Navarra: Thomson Reuters Aranzadi.

FUERTES LÓPEZ, M. (2014): "La necesidad de un procedimiento para combatir el fraude. (A propósito de la Oficina Europea de Lucha contra el fraude, OLAF)", en Revista de Administración Pública, RAP, núm. 195, págs. 269-301. URL: http://www.cepc.gob.es/publicaciones/revistas/revistaselectronicas?IDR=1\&IDN=1331\&I $D A=37173$

GALLEGO CÓRCOLES, I. (2017): "Breves notas sobre el uso de medios electrónicos en la contratación pública", en MARTIN DELGADO, I. (dir.): La reforma de la administración electrónica: una oportunidad para la innovación desde el Derecho, págs. 323-342. Madrid: Instituto Nacional de Administración Pública, INAP.

GAMERO CASADO, E. (dir), FERNÁNDEZ RAMOS, S. y VALERO TORRIJOS, J. (coords.) (2017): Tratado de Procedimiento Administrativo Común y Régimen Jurídico Básico del Sector Público, págs. 171 y ss. Valencia: Tirant lo Blanch.

GAMERO CASADO, E. y FERNÁNDEZ RAMOS, S. (2018): Manual básico de Derecho Administrativo, pág. 802. Madrid: Tecnos.

GIL CONDÓN, M. A. (2018): "La nueva regulación del procedimiento administrativo y su proyección e incidencia en los procedimientos en materia de contratación”, en GIMENO FELIÚ, J. M. ${ }^{a}$ (dir.): Estudio Sistemático de la Ley de Contratos del Sector Público, págs. 1.715-1.767. Navarra: Thomson Reuters Aranzadi.

GIMENO FELIÚ, J. M. a (2017): "Medidas de prevención de corrupción y refuerzo de la transparencia en la contratación pública", en Revista de Estudios de la Administración Local y Autonómica, REALA. Nueva Época, núm. 7, págs. 45-67. DOI: https://doi.org/10.24965/reala.v0i7.10419. 
REALA. Nueva Época - N. 12, octubre-marzo 2019 - ISSN: 1989-8975 - DOI: 10.24965/reala.i12.10714 - [Págs. 6-25]

La transparencia como principio vertebrador de la contratación pública: significado y problemas de articulación normativa

Isabel González Ríos

GIMENO FELIÚ, J. M. ${ }^{a}$ (2018): "La nueva Ley de Contratos del Sector Público: hacia un modelo de contratación pública transparente”, en Contratación Administrativa Práctica: Revista de la Contratación Administrativa y de los Contratistas, núm. 153, págs. 34-39.

GIMENO FELIÚ, J. M. ${ }^{a}$ (2013): "Las nuevas directivas -cuarta generación- en materia de contratación pública. Hacia una estrategia eficiente en compra pública", en Revista Española de Derecho Administrativo, REDA, núm. 159, págs. 39-106.

GONZÁLEZ PÉREZ, J. (2014): Corrupción, ética y moral en las Administraciones públicas. Navarra: Civitas.

GONZÁLEZ RIOS, I. (2018): "La vis expansiva del concepto «procedimiento administrativo común» en nuestros días”, en Revista de Administración Pública, RAP, núm. 207, págs. 127-175. DOI: https://doi.org/10.18042/cepc/ rap.207.06.

GUICHOT REINA, E. (2016): "Reflexiones acerca de la aplicación de la nueva normativa sobre transparencia pública", en Administración de Andalucía: Revista Andaluza de Administración Pública, RAAP, núm. 94, págs. 89-106. URL: http://www.juntadeandalucia.es/institutodeadministracionpublica/institutodeadministracionpublica/servlet/ descarga?up $=112053$.

GUICHOT REINA, E. (coord.) (2014): Transparencia, acceso a la información pública y buen gobierno: estudio de la Ley 19/2013, de 9 de diciembre. Madrid: Tecnos.

GUICHOT REINA, E. (2014): “Transparencia: aspectos generales”, en GUICHOT REINA, E. (coord.): Transparencia, acceso a la información pública y buen gobierno: estudio de la Ley 19/2013, de 9 de diciembre, págs. 35-62. Madrid: Tecnos.

HUERGO LORA, A. J. (2015): "Las leyes 39 y 40/2015. Su ámbito de aplicación y la regulación de los actos administrativos", en El Cronista del Estado Social y Democrático de Derecho, núm. 63, págs. 4-13.

IGLESIAS REY, P. (2018): "Transparencia en la contratación pública", en MESTRE DELGADO, J. F. y MANENT ALONSO, L. (dirs.) y TENHAEFF LACKSCHEWITZ, S. (coord.): La Ley de Contratos del Sector Público Ley 9/2017, de 8 de noviembre: aspectos novedosos, págs. 295-329. Valencia: Tirant lo Blanch.

LÓPEZ MENUDO, F. (2016): "Significación de los conceptos de procedimiento común y de régimen jurídico. Razones y sinrazones de la reforma”, en LÓPEZ MENUDO, F. (dir.): Innovaciones en el procedimiento administrativo común y régimen jurídico del sector público, págs. 13-39. Sevilla: Editorial Universidad de Sevilla.

MALARET I GARCÍA, E. (2016): "El nuevo reto de la contratación pública para afianzar la integridad y el control: reforzar el profesionalismo y la transparencia", en Revista Digital de Derecho Administrativo, núm. 15, págs. 2160. DOI: $h$ ttps://doi.org/10.18601/21452946.n15.04.

MARTÍN DELGADO, I. (2017): "Contratación pública y procedimiento administrativo común: una reflexión general sobre el uso obligado de los medios electrónicos en los procedimientos de contratación”, en Contratación Administrativa Práctica: Revista de la Contratación Administrativa y de los Contratistas, núm. 147, págs. 10-17.

MARTÍN DELGADO, I. (2018): "El uso de los medios electrónicos en la contratación pública", en GIMENO FELIÚ, J. M. ${ }^{a}$ (dir.): Estudio Sistemático de la Ley de Contratos del Sector Público, págs. 1.657-1.714. Navarra: Thomson Reuters Aranzadi.

MARTÍN DELGADO, I. (2010): "El procedimiento administrativo en el Derecho de la Unión Europea", en Revista de Derecho de la Unión Europea, núm. 19, págs. 99-143. URL: http://e-spacio.uned.es/fez/view/ bibliuned:REDUE-2010-19-5050.

MARTÍNEZ FERNÁNDEZ, J. M. (2016): Contratación pública y transparencia: medidas prácticas para atajar la corrupción en el marco de la nueva regulación. Las Rozas, Madrid: Wolters Kluwer. El Consultor de los Ayuntamientos.

MEDIDA ARNAIZ, T. (2016): "La necesidad de reformar la legislación sobre contratación pública para luchar contra la corrupción: las obligaciones que nos llegan desde Europa", en Revista Vasca de Administración Pública. Herri-Arduralaritzako Euskal Aldizkaria, RVAP, núm. 104-2, Monográfico: La lucha contra la corrupción política, págs. 77-113.

MEDINA GUERRERO, M. (2018): “La transparencia y la protección de datos en la encrucijada”, en Revista Española de Transparencia, RET, núm. 6, págs. 33-36. URL: https://revistatransparencia.com/ojs/index.php/ret/article/ view/33/22.

MELLADO RUIZ, L. (2017): “Contratación pública y corrupción: a la búsqueda de la regeneración democrática mediante la transparencia”, en GÓMEZ RIVERO, M. C. y BARRERO ORTEGA, A. (dirs.): Regeneración democrática y estrategias penales en la lucha contra la corrupción, págs. 209-252. Valencia: Tirant Lo Blanch.

MELLADO RUIZ, L. (2017): El principio de transparencia integral en la contratación del sector público. Valencia: Tirant lo Blanch.

MESEGUER YEBRA, J. (2014): "El procedimiento administrativo para el acceso a la información pública”, en Revista Jurídica de Castilla y León, núm. 33, Monográfico: Transparencia, acceso a la información pública y buen gobierno. Análisis de la cuestión tras la Ley 19/2013. URL: https://www.jcyl.es/web/jcyl/AdministracionPublica/es/ Plantilla100Detalle/1215245063566/1215245063566/1284319346975/Redaccion.

MORENO MOLINA, J. A. (2019): “Los principios generales de la LCSP 2017", en Gabilex: Revista del Gabinete Jurídico de Castilla-La Mancha, vol. I, núm. Extra 1 Un año de compra pública con la LCSP, pág. 21-34. URL: https://gabilex.castillalamancha.es/numeros/no-extraordinario-un-ano-de-compra-publica-con-la-Icsp-volumen-i. 
REALA. Nueva Época - N. 12, octubre-marzo 2019 - ISSN: 1989-8975 - DOI: 10.24965/reala.i12.10714 - [Págs. 6-25]

La transparencia como principio vertebrador de la contratación pública: significado y problemas de articulación normativa

Isabel González Ríos

MORENO MOLINA, J. A. (2017): "Novedades en relación con los principios generales de la contratación pública", en El Consultor de los Ayuntamientos y de los Juzgados, núm. 23, págs. 2.799-2.811.

ORTEGA CARBALLO, C. (2006): "Los registros administrativos como instrumentos de publicidad y transparencia en la gestión de la contratación pública”, en Documentación Administrativa, DA, núm. 274-275, págs. 93-113. DOI: https://doi.org/10.24965/da.v0i274-275.9569.

PAREJO ALFONSO, L. (2000): "El procedimiento administrativo comunitario", en PAREJO ALFONSO, L.: Manual de Derecho Administrativo Comunitario, págs. 229-278. Madrid: Centro de Estudios Ramón Areces.

PAREJO ALFONSO, L. (1993): "Objeto, ámbito de aplicación y principios generales de la Ley de Régimen Jurídico de las Administraciones públicas y del procedimiento común”, en LEGUINA VILLA, J. y SÁNCHEZ MORÓN, M. (dirs.): La nueva Ley de Régimen jurídico de las Administraciones públicas y del procedimiento administrativo común. Madrid: Tecnos.

PAREJO ALFONSO, L. y VAQUER CABALLERÍA, M. (dirs.) (2018): Estudios sobre el procedimiento administrativo I: Derecho comparado. Valencia: Tirant lo Blanch.

PIÑAR MAÑAS, J. L. (2014): "Transparencia y derecho de acceso a la información pública: algunas reflexiones en torno al derecho de acceso en la Ley 19/2013 de Transparencia, acceso a la información pública y buen gobierno", en Revista Catalana de Dret Public, núm. 49, pág. 1-19. DOI: http://dx.doi.org/10.2436/20.8030.01.29.

PONCE SOLÉ, J. (2016): "Mecanismos de resolución alternativa de conflictos y su aplicación en el ámbito de la Administración tributaria", en LÓPEZ RAMÓN, F. (coord.): Las vías administrativas de recurso a debate: Actas del XI Congreso de la Asociación Española de Profesores de Derecho Administrativo, págs. 204-232. Zaragoza, 5 y 6 de febrero de 2016. Madrid: Instituto Nacional de Administración Pública, INAP.

PRIETO ROMERO, C. (2011): "Medidas de transparencia y ética pública: los códigos éticos, de conducta o buen gobierno”, en Anuario de Gobierno Local, núm. 1, págs. 315-347. URL: http://repositorio.gobiernolocal.es/xm/ui/ handle/10873/1256

RAMS RAMOS, S. (2016): "El procedimiento de ejercicio del derecho de acceso a la información pública”, en Revista General de Derecho Administrativo, RGDA, núm. 41.

RAZQUIN LIZARRAGA, M. M. a (2015): "Las nuevas Directivas sobre contratación pública de 2014: aspectos clave y propuestas para su transposición en España”, en Revista Administración Pública, RAP, núm. 196, págs. 97-135. URL: $h$ ttp://Www.cepc.gob.es/publicaciones/revistas/revistaselectronicas? IDR=1\&IDN=1339\&IDA=37303.

RAZQUIN LIZARRAGA, M. M. ${ }^{a}$ (2018): "Los principios generales de la contratación pública”, en GAMERO CASADO, E. y GALLEGO CÓRCOLES, I. (dirs.): Tratado de Contratos del Sector Público, págs. 195-208. Valencia: Tirant lo Blanch.

RAZQUIN LIZARRAGA, M. M. a (2018): "El principio de confidencialidad en la contratación pública", en GIMENO FELIÚ, J. M. ${ }^{a}$ (dir.): Estudio sistemático de la Ley de Contratos del Sector Público, págs. 867-911. Navarra: Thomson Reuters Aranzadi.

RODRÍGUEZ ARANA, J. (1995): “La transparencia en la Administración Pública”, en Revista Vasca de Administración Pública. Herri-Arduralaritzako Euskal Aldizkaria, RVAP, núm. 42, págs. 447-466.

RODRÍGUEZ ARANA, J. (2016): "Los principios del derecho global de la contratación pública”, en Revista Española de Derecho Administrativo, REDA, núm. 179, págs. 29-54. DOI: https://doi.org/10.22235/rd.v0i13.1218.

RODRÍGUEZ-ARANA MUÑOZ, J. y SENDÍN GARCÍA, M. A. (2014): Transparencia, acceso a la información y Buen Gobierno: comentarios a la Ley 19-2013, de 9 de diciembre, de Transparencia, acceso a la información pública y buen gobierno. Granada: Comares.

SÁNCHEZ MORÓN, M. (2017): Derecho Administrativo. Madrid: Tecnos.

TOLIVAR ALAS, L. (2019): "Contratación pública: corrupción y transparencia en una sociedad digital", en DEL GUAYO CASTIELLA, I. y FERNÁNDEZ-CARBALLAL, A. (coords.): Los desafíos del derecho público en el siglo XXI: libro conmemorativo del XXV aniversario del acceso a la Cátedra del Profesor Jaime Rodríguez-Arana Muñoz, págs. 895-914. Madrid: Instituto Nacional de Administración Pública, INAP.

TRONCOSO REIGADA, A. (dir.) (2017): Comentarios a la Ley de Transparencia, Acceso a la Información Pública y Buen Gobierno. Navarra: Thomson Reuters Aranzadi.

VALERO TORRIJOS, J. y FERNÁNDEZ SALMERÓN, M. (coords.) (2014): Régimen jurídico de la transparencia del sector público: del derecho de acceso a la reutilización de la información. Navarra: Thomson Reuters Aranzadi.

VELASCO RICO, C. I. (2014): "La cuestión competencial en la Ley 19/2013, de 9 de diciembre: ¿de qué margen disponen las CCAA en materia de transparencia, acceso a la información pública y buen gobierno?", en Revista Jurídica de Castilla y León, núm. 33, Monográfico: Transparencia, acceso a la información pública y buen gobierno. Análisis de la cuestión tras la Ley 19/2013. URL: https://www.jcyl.es/web/jcyl/AdministracionPublica/es/ Plantilla100Detalle/1215245063566/1215245063566/1284319395584/Redaccion.

VV.AA (2017): Los límites al derecho de acceso a la información pública. Madrid: Instituto Nacional de Administración Pública, INAP. 